Article

\title{
Investigation of the Microstructure and Compressibility of Biodegradable Fe-Mn-Cu/W/Co Nanostructured Alloy Powders Synthesized by Mechanical Alloying
}

\author{
Hany R. Ammar 1,2,*, Subbarayan Sivasankaran ${ }^{1}$ (D) and Abdulaziz S. Alaboodi ${ }^{1}$ (D) \\ 1 Department of Mechanical Engineering, College of Engineering, Qassim University, \\ Buraydah 51452, Saudi Arabia; sivasankaran@qec.edu.sa (S.S.); alaboodi@qec.edu.sa (A.S.A.) \\ 2 Metallurgical and Materials Engineering Department, Faculty of Petroleum and Mining Engineering, \\ Suez University, Suez 43511, Egypt \\ * Correspondence: hanyammar@qec.edu.sa
}

check for updates

Citation: Ammar, H.R.;

Sivasankaran, S.; Alaboodi, A.S.

Investigation of the Microstructure and Compressibility of Biodegradable Fe-Mn-Cu/W/Co Nanostructured Alloy Powders Synthesized by Mechanical Alloying. Materials 2021, 14, 3088. https://doi.org/10.3390/ ma14113088

Academic Editor: Lluïsa Escoda

Received: 6 May 2021

Accepted: 2 June 2021

Published: 4 June 2021

Publisher's Note: MDPI stays neutral with regard to jurisdictional claims in published maps and institutional affiliations.

Copyright: (c) 2021 by the authors. Licensee MDPI, Basel, Switzerland. This article is an open access article distributed under the terms and conditions of the Creative Commons Attribution (CC BY) license (https:/ / creativecommons.org/licenses/by/ $4.0 /)$.

\begin{abstract}
In this research work, the nanostructured Fe-Mn (BM0), Fe-Mn-Cu (BM1), Fe-Mn-W (BM2), and Fe-Mn-Co (BM3) biodegradable alloys were successfully synthesized using mechanical alloying. The microstructure of the synthesized alloys was examined using XRD, SEM equipped with EDS, and HRTEM techniques. The results obtained based on these techniques confirmed the development of nanostructured BM0, BM1, BM2, and BM3 alloys and homogenous solid solutions with an even elemental dispersion. The compressibility of the synthesized alloys was investigated experimentally and empirically in the as-milled conditions and after applying a stress relief treatment $\left(150^{\circ} \mathrm{C}\right.$ for $\left.1 \mathrm{~h}\right)$. The load applied for compaction experiments ranged from 25-1100 MPa with a rate of $1 \mathrm{~mm} / \mathrm{min}$. According to the experimentation performed in the current study, the relative density of the as-milled BM0, BM1, BM2, and BM3 alloys was $72.90 \%$ and $71.64 \%, 72.32 \%$, and $72.03 \%$, respectively. After applying the stress relief treatment, the density was observed to increase to $75.23 \%, 77.10 \%, 72.65 \%$, and $72.86 \%$ for BM0-S, BM1-S, BM2-S and BM3-S samples, respectively. A number of compaction models were tested to identify the optimum models for predicting the compressibility behavior of nanostructured Fe-Mn, Fe-Mn-Cu, Fe-Mn-W, and Fe-Mn-Co alloys in the as-milled and stress-relieved conditions.
\end{abstract}

Keywords: Fe-Mn (Cu-W-Co) alloy; biodegradable materials; microstructure; compressibility

\section{Introduction}

Recently, biodegradable metals and alloys are being widely used as load-bearing temporary implants in medical applications. The function of these materials is to mechanically support a treated tissue during a curative course and then degrade gradually without any remaining implantation; therefore, the recovery process can be completed without any further surgical treatments [1]. Biodegradable materials have required high strength and high degradation rate in addition to the compatibility. Accordingly, several metals are being used as biomaterials such as $\mathrm{Fe}, \mathrm{Mg}, \mathrm{Zn}$, and their alloys. Iron and its alloys are promising biodegradable materials, for instance stent implementation, due to their acceptable strength and stiffness; however, the low corrosion rate of biodegradable iron alloys is one of the major concerns of these materials [2-4]. Several studies were conducted to examine the mechanical behavior and the corrosion behavior of iron-based implant materials [5-8]. These studies focused on investigating the influence of alloy production techniques and the effect of adding various alloying elements such as manganese, silicon, sulfur, and carbon in order to examine the mechanical behavior and degradability of these alloys [9-12]. Bagha et al. [13] discussed the degradability of iron based biodegradable implant materials that were produced by means of ball milling and spark-plasma sintering techniques. The authors have reported that the corrosion rate of these materials 
was accelerated using appropriate addition of $\mathrm{Mn}$ and $\mathrm{Ag}$, as alloying elements. The examined alloy displayed high shear strength of $420 \mathrm{MPa}$ and produced the average strain of $66 \%$. Sotoudehbagha et al. [14] have studied various synthesizing method to produce iron-based implant materials and further, the authors have varied different elemental composition. The authors have produced novel iron-based materials consisting of 30 weight fraction of manganese and around 3 weight fraction of silver using ball milling technique. The results revealed that the alloy contained $3 \mathrm{wt} . \%$ silver has exhibited the best properties as compared with the other alloys. The investigated properties include the shear strength, micro-hardness, corrosion rate, and relative density. On the other hand, they have reported that the optimal cytotoxicity and antibacterial behavior were obtained when adding $1 \mathrm{wt} . \%$ silver. Bagha et al. [15] studied the mechanical behavior, corrosion rate, and biocompatibility of a nanocrystalline Fe-35 wt.\% Mn biodegradable alloy. The alloy was synthesized by means of ball milling technique and consolidated by traditional cold pressing and sintering. The milled alloy has exhibited higher hardness, enhanced compression strength, lower rate of corrosion, and improved cell adhesion, as compared to un-milled samples. Safaie et al. [16] successfully synthesized a solid solution of nanostructured iron-based alloy mixed with 30 weight fraction of manganese using ball milling technique. The authors have used the ball milling parameters of $10 \mathrm{~h}$ milling time, and 30:1 ball-to-powder ratio. Sikora-Jasinska et al. [17] developed Fe- $\mathrm{Mg}_{2} \mathrm{Si}$ composite for the applications of biodegradable implants with improved mechanical characteristics and increased the corrosion resistance. The produced composite of Fe- $\mathrm{Mg}_{2} \mathrm{Si}$ were synthesized using ball milling technique and then consolidated by hot rolling. The results explained that the incorporation of one weight fraction of magnesium silicide $\left(\mathrm{Mg}_{2} \mathrm{Si}\right)$ in the iron matrix was improved the corrosion resistance. Mouzou et al. [18] investigated the biodegradability performance of Fe-20Mn-1.2C alloy in various corrosive solutions. The alloys were fabricated industrially by casting process followed by hot rolling. The highest degradation rate was reported when using commercial Hank's solution as a corrosion media while the lowest rate was found when using a corrosive media of Dulbecco's modified solution. Mandal et al. [19] developed a novel Fe-Mn-Cu alloy for fracture fixation with improved anti-microbial behavior. The authors have developed different compositions of iron alloyed with various percentage of manganese and copper in which the maximum manganese content was $35 \mathrm{wt} . \%$ and the copper content was 10\%. These alloys were manufactured using high-energy mechanical alloying process followed by compaction and sintering. It was reported that adding up to $10 \mathrm{wt} . \% \mathrm{Cu}$ resulted in increasing the corrosion rate with 6 times more than the base alloy. Furthermore, increasing the $\mathrm{Cu}$-level up to $5 \mathrm{wt} . \%$ resulted in a significant increase in the hardness of the investigated alloys. Additionally, increasing Cu-content led to improved anti-microbial properties. Faruk Mert [20] has investigated the tribological behavior of magnesium-based biodegradable alloy (AZ1B hot rolled alloy) for implant applications. The sliding wear test was conducted using pin-on-disc apparatus in which the author has varied the load starting from $10 \mathrm{~N}$ to $80 \mathrm{~N}$, the sliding velocity varied from $0.25 \mathrm{~m} / \mathrm{s}$ to $2.5 \mathrm{~m} / \mathrm{s}$, and the maximum sliding distance was $5000 \mathrm{~m}$. Finally, the author has found that the hot rolled AZ1B magnesium-based implant materials were produced more wear resistant. Powder metallurgy $(\mathrm{P} / \mathrm{M})$ process is a common one by which several metallic products are being manufactured commercially for aircraft, space craft, automotive, and structural components [21]. Achievement of near net shape and making of complex products are the main features of $\mathrm{P} / \mathrm{M}$ process [22]. Study of input metal powders before processing is very important as the powder compressibility influence the mechanical performance of $\mathrm{P} / \mathrm{M}$ products [23]. Further, the compressibility of alloy powders is considered as a substantial stage in industrial application when fabricating $\mathrm{P} / \mathrm{M}$ products [24]. The compaction behavior of alloy powders is affected by several factors such as the composition, size and shape of the powders, compaction pressure, compaction rate, density of powders, and flow properties of the powders [25-27]. Accordingly, the compressibility of the synthesized alloys was investigated for the processed powders in the as-milled conditions and after applying a stress relief treatment. 
Fe-Mn-based alloys are promising candidates for biodegradable applications. The biodegradable materials require high strength, acceptable ductility, and high rate of degradation. Several alloying elements were used to improve the mechanical properties and increase the degradation rate [28,29]. The additions of $\mathrm{Cu}, \mathrm{W}$, and $\mathrm{Co}$, as alloying elements to an Fe-Mn system have a strong potential to improve the mechanical properties and degradation rate of these biodegradable materials. The present study was conducted for developing and investigating the behavior of $\mathrm{Fe}-\mathrm{Mn}-\mathrm{Cu} / \mathrm{W} / \mathrm{Co}$ nanostructured biodegradable materials. The purpose of the present study includes: (i) synthesizing Fe-Mn, Fe$\mathrm{Mn}-\mathrm{Cu}, \mathrm{Fe}-\mathrm{Mn}-\mathrm{W}$, and Fe-Mn-Co nanostructured biodegradable alloys by mechanical alloying; (ii) microstructure investigation of the processed alloys using XRD, HRSEM equipped with EDS, and HRTEM; (iii) experimental investigation of the compressibility of the processed alloys in the as-milled condition and after applying stress relief treatment to evaluate the attained relative density of the examined alloys; and (iv) empirical investigation of the compaction behavior by a number of linear and non-linear models for expecting the green density of the produced nanocrystalline alloys in the as-milled and stress relieved conditions.

\section{Materials and Methods}

\subsection{Synthesis of $\mathrm{Fe}-\mathrm{Mn}$, $\mathrm{Fe}-\mathrm{Mn}$-Cu, $\mathrm{Fe}-\mathrm{Mn}$-W, and $\mathrm{Fe}-\mathrm{Mn}$-Co Alloys}

$\mathrm{Fe}, \mathrm{Mn}, \mathrm{Cu}, \mathrm{W}$, and Co elemental powders were used for mechanical alloying (MA) process. These powders displayed a high purity more than $99.9 \%$ and an average particle size less than $44 \mu \mathrm{m}$. Table 1 shows the composition in atomic (at.\%) and weight (wt.\%) percent of the produced Fe-Mn, Fe-Mn-Cu, Fe-Mn-W, and Fe-Mn-Co alloys. The laboratory ball mill of the type Pulverisette 5/2 classic line was used in performing the mechanical alloying of the starting powders, where two tungsten carbide (WC) vails with a capacity of $250 \mathrm{~mL}$ (for each vail) and WC balls with $10 \mathrm{~mm}$ diameter were used in the present study. The mixed elemental powders were subjected to MA for five hours with a speed of $300 \mathrm{rpm}$ and BPR of 10:1. The MA was accomplished in a liquid grinding medium of toluene (purity $>99.9 \%$ ) to avoid cold welding and oxidization of the mechanically alloyed (MAed) powders [21,30]. MA was completed based on the frequent milling cycles that comprises $15 \mathrm{~min}$ milling in the forward direction followed by $15 \mathrm{~min}$ pause and thereafter $15 \mathrm{~min}$ milling in the reverse direction followed by a pause of $15 \mathrm{~min}$; this milling cycle was repetitive to achieve continuous MA process with the least heat buildup inside the vails. Some quantity of synthesized powders was stress relieved at $150^{\circ} \mathrm{C}$ for $1 \mathrm{~h}$ under vacuum using R120/500/13 model tube furnace (Nabertherm, Lilienthal, Germany). The notation used in the samples are BM0 (Fe-65, Mn-35, at.\%), BM1 (Fe-65, Mn-32, Cu-3, at.\%), BM2 (Fe-65, Mn-32, W-3, at.\%), and BM3 (Fe-65, Mn-32, Co-3, at.\%).

Table 1. Composition of the produced Fe-Mn, Fe-Mn-Cu, Fe-Mn-W, and Fe-Mn-Co alloys.

\begin{tabular}{cccccc}
\hline \multirow{2}{*}{ Alloy Code } & \multicolumn{5}{c}{ Composition in at.\% (Wt.\%) } \\
\cline { 2 - 5 } & Fe & Mn & Cu & W & Co \\
\hline BM0 * & $65.00(65.36)$ & $35.00(34.64)$ & - & - & - \\
\hline BM1 * & $65.00(65.07)$ & $32.00(31.51)$ & $3.00(3.42)$ & - & - \\
\hline BM2 * & $65.00(61.12)$ & $32.00(29.60)$ & - & $3.00(9.29)$ & - \\
\hline BM3 * & $65.00(65.23)$ & $32.00(31.59)$ & - & - & $3.00(3.18)$ \\
\hline *BM0-S, BM1-S, BM2-S, and BM3-S codes will be used instead of BM0, BM1, BM2, and BM3, respectively, for the
\end{tabular}

same alloys subjected to stress relief treatment.

\subsection{Microstructural Characterization of the Processed Fe-Mn, Fe-Mn-Cu, Fe-Mn-W, and $\mathrm{Fe}-\mathrm{Mn}$-Co Alloys}

The observed phases, crystallite size, and lattice strain of BM0, BM1, BM2, and BM3 alloys were identified using XRD (Empyrean, Malvern Panalytical, Malvern, UK). Cu-k $\alpha$ source of radiation was applied to examine the samples with $0.6^{\circ} / \mathrm{min}$ rate and $0.01^{\circ}$ step 
with $2 \theta$ range of $20^{\circ}$ to $90^{\circ}$. The attained data from XRD experiment was studied by X'Pert High Score Plus software (version 2.2b (2.2.2), Furthermore, the same software was used to calculate the lattice strain and crystallite size based on Debye-Scherer concept. Apreo FEG-HR-SEM equipped with SE, BSE, and EDS detectors was used for microstructure analysis of the BM0, BM1, BM2, and BM3 alloys. The powders size and morphology, the elemental dispersion of the processed alloys in both powders and compact forms were characterized. The formation of nanocrystalline nature of four bio-degradable alloys (BM0, BM1, BM2, and BM3) were examined using high-resolution transmission electron microscope (HRTEM, JEOL 3010, Akishima, Tokyo, Japan). Before HRTEM examination, the synthesized powders were dissolved in an ethanol solution, poured over the copper grid, and then placed inside the machine. The used HRTEM was attached with EDAX by which the presence of various elements in BM1 and BM3 alloys, as an example, were also taken.

\subsection{Compressibility of the Processed $\mathrm{Fe}-\mathrm{Mn}$, Fe-Mn-Cu, Fe-Mn-W, and Fe-Mn-Co Alloys}

The compressibility of the synthesized alloys was investigated experimentally to study the densification behavior of these alloy powders. The compaction behavior was examined for the processed powders under various loads, ranged from $25 \mathrm{MPa}$ to $1100 \mathrm{MPa}$, in the as-milled conditions and after applying stress relief treatment. The maximum pressure was decided after several trails where increasing the pressure more than $1100 \mathrm{MPa}$ in the present study resulted in cracking and breaking the green samples. The stress relief treatment was carried out using a tube furnace (model: R120/500/13, Nabertherm, Lilienthal, Germany) where the processed powders were heat treated at $150{ }^{\circ} \mathrm{C}$ for one hour under vacuum $(-5 \mathrm{psi})$ and controlled argon atmosphere to prevent powder oxidation. The temperature and time of the heat treatment were selected based on the idea of applying a relatively lower temperature $\left(150^{\circ} \mathrm{C}\right)$ to make use of this treatment in improving the compressibility of the processed powders without causing major changes in the microstructure constituents and features of the alloys that was attained from the mechanical alloying process such as crystallite size and structure homogeneity. The die used in compressibility test was made of hardened $\mathrm{H} 13$ tool steel with $15 \mathrm{~mm}$ inner diameter and upper/bottom plungers (outer diameter of $15 \mathrm{~mm}$ ). The compressibility test was accomplished in MTS universal testing machine with $1 \mathrm{~mm} / \mathrm{min}$ of crosshead speed. The processed powders were compacted at different pressures to generate density-pressure curves. The green compacts density was measured according to Archimedes' conception where an average of three measurements was recorded. In addition to the experimental study of the powder densification, the compressibility of the as-milled and stress relieved powders was further examined by empirical formulas to determine the optimum empirical equation for expecting the relative density of the fabricated alloys [27,31]. A schematic representation of the powders processing and compaction of the developed nanocrystallite materials is shown in Figure 1. This Figure shows the steps of performing the present study where the starting powders of each alloy system were mechanically alloyed. Thereafter, the obtained processed powders were examined using XRD, HRSEM equipped with EDS, and HRTEM. Specific quantities of the processed powders were heat treated using a tube furnace equipped with a vacuum pump and a controlled atmosphere system. The compressibility experiment was conducted using MTS (Eden Prairie, MN, USA) machine to study the compressibility of the as-milled and the heat treated powders. Ultimately, the relative density and microstructure analysis of the green samples were evaluated. 


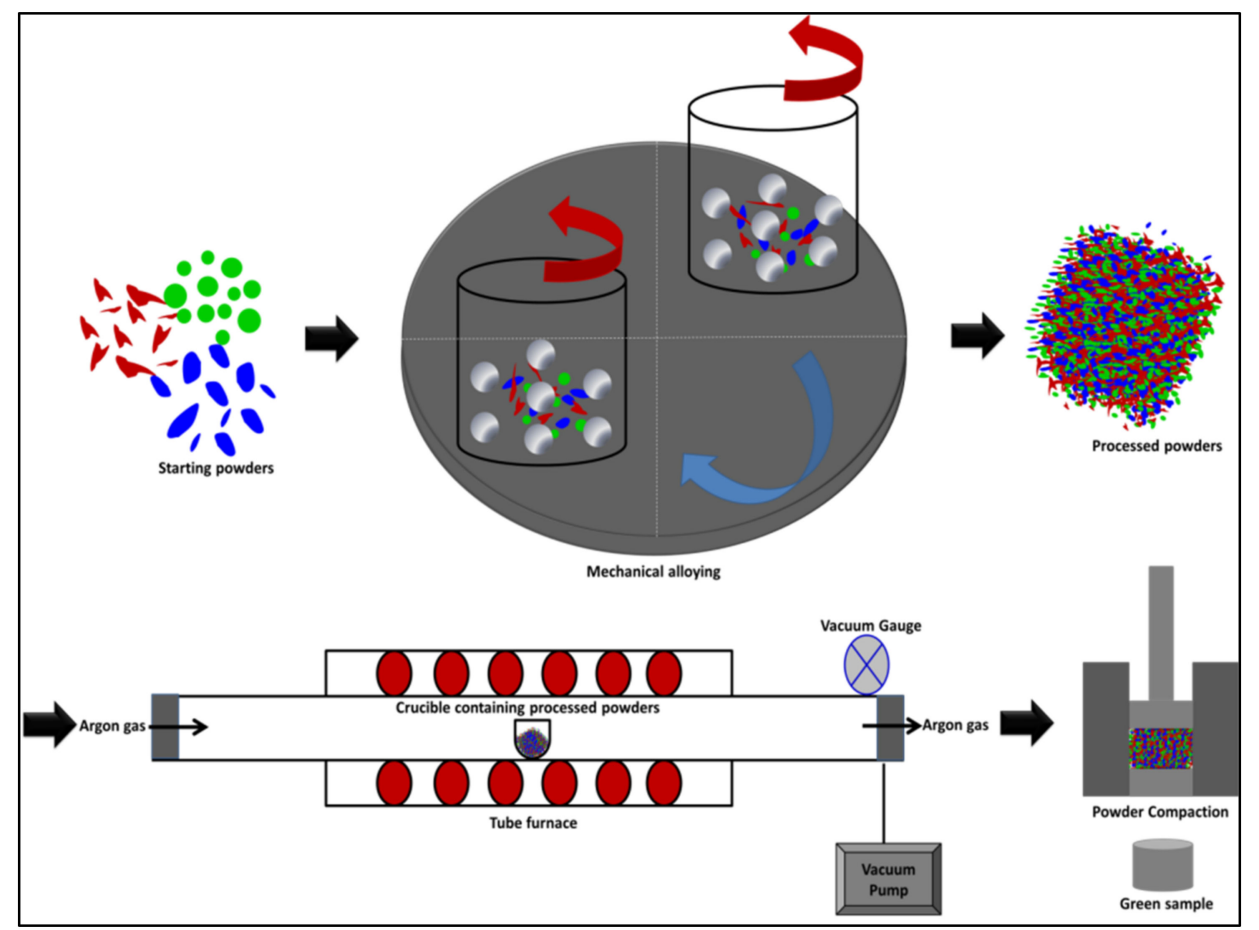

Figure 1. A schematic representation of the powders processing and compaction in this study.

\section{Results and Discussion}

The present study aims to synthesizing Fe-Mn, Fe-Mn-Cu, Fe-Mn-W, and Fe-Mn-Co nanostructured biodegradable alloys by mechanical alloying; microstructure investigation of the processed alloys using XRD, high resolution SEM equipped with EDS technique, and HRTEM; and studying the compressibility of the processed alloys experimentally and empirically in the as-milled condition and after applying stress relief treatment.

\subsection{Microstructural Characterization of the Processed Fe-Mn, Fe-Mn-Cu, Fe-Mn-W, and $\mathrm{Fe}-\mathrm{Mn}$-Co Alloys}

The average particle size of the as-received powders was $\leq 44 \mu \mathrm{m}$. The morphology of the as-received $\mathrm{Fe}, \mathrm{Mn}, \mathrm{Cu}, \mathrm{W}$, and Co powders was examined using FEG-HR-SEM and the collected images are presented in Figure 2. Figure 2a,b illustrate the dendritic morphology of Fe particles at low and high magnification, respectively. Figure 2c,d show the facet shape of Mn powders at low and high magnification, respectively. Figure 2e,f present the spherical shape of $\mathrm{Cu}$ powders at low and high magnification, respectively. Figure $2 \mathrm{~g}, \mathrm{~h}$ present the polygonal appearance of $\mathrm{W}$ powders at low and high magnification, respectively. Figure $2 \mathrm{i}, \mathrm{j}$ display the dendritic shape of Co powders at low and high magnification, respectively. The chemical composition of the powders was confirmed by point analysis using EDS where the resultant EDS spectrum corresponding to each powder was inserted in the bottom right-hand corner of the SE images taken at low magnification, as presented in Figure 2. The BSE images presented in Figure 3a,c,e,g illustrate the morphology of the MAed BM0, $\mathrm{BM} 1, \mathrm{BM} 2$, and BM3 alloys in the powder form where an almost rounded-shape of the processed powders was attained. The high magnification BSE images of the circled regions in Figure $3 \mathrm{a}, \mathrm{c}, \mathrm{e}, \mathrm{g}$ are presented in Figure $3 \mathrm{~b}, \mathrm{~d}, \mathrm{f}, \mathrm{h}$ to confirm the formation of a homogenous solid solution in the processed BM0, BM1, BM2, and BM3 alloys, where the synthesized powders revealed uniform gray color indicating the even dispersion/dissolution of the mixed elements of the developed alloys. The coarse aggregates shown in Figure 3a,c,e,g consist of fine particulates as a result of the repetitive rupturing and welding of the Maed powders. Examples of the fine particles that form the large agglomerate are arrowed in Figure $3 \mathrm{~b}, \mathrm{~d}, \mathrm{f}, \mathrm{h}$. This mechanism occurs during the MA process till a homogenous solid solution of the mixed elements was formed. 

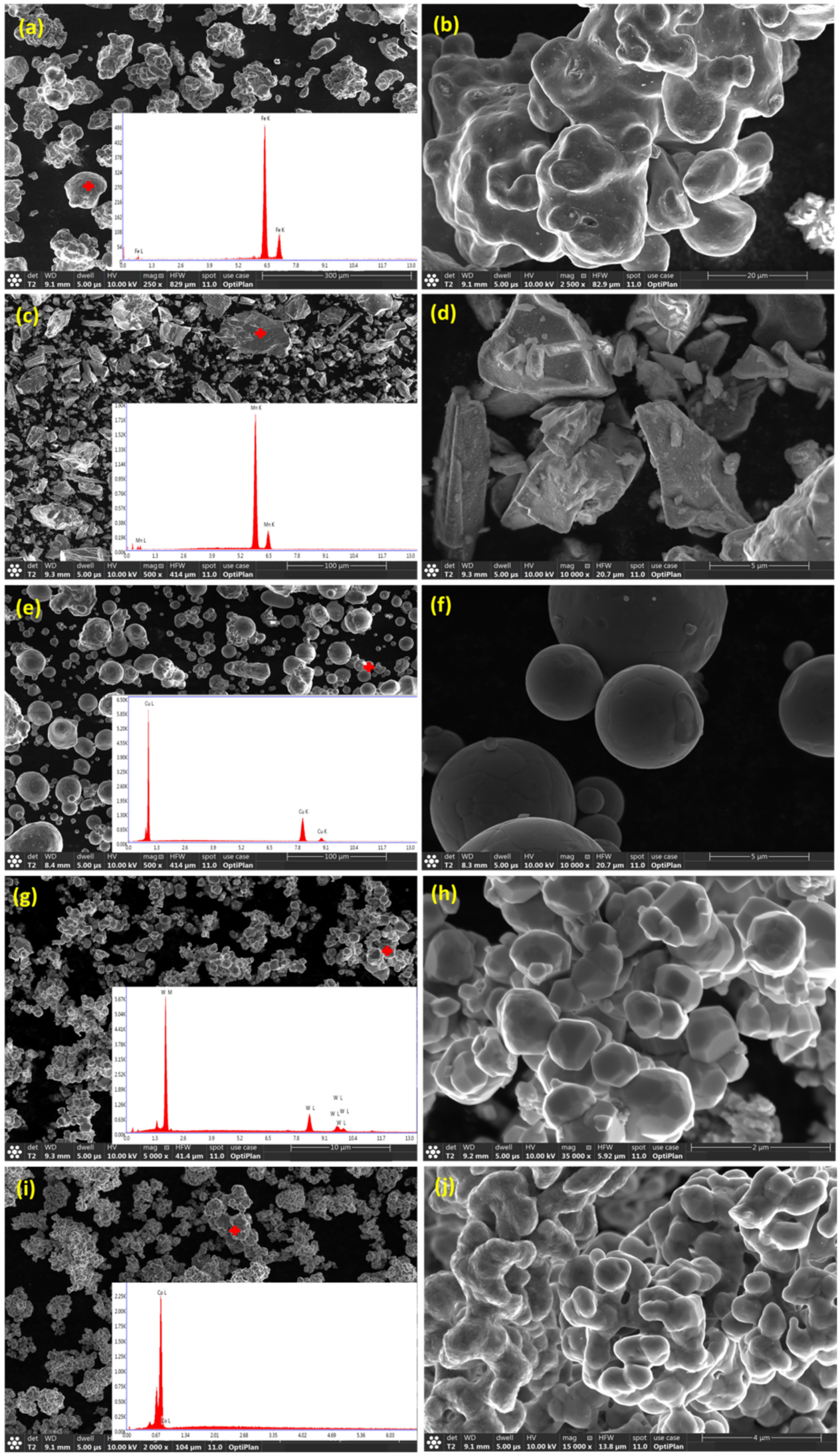

Figure 2. SE images of the as-received powders morphology at low (left) and high magnification (right): (a,b) Fe particles; (c,d) Mn powders; (e,f) Cu powders; (g,h) W powders; and (i,j) Co powders. The insets at the low magnification images show the EDS spectrum of the corresponding powders. 

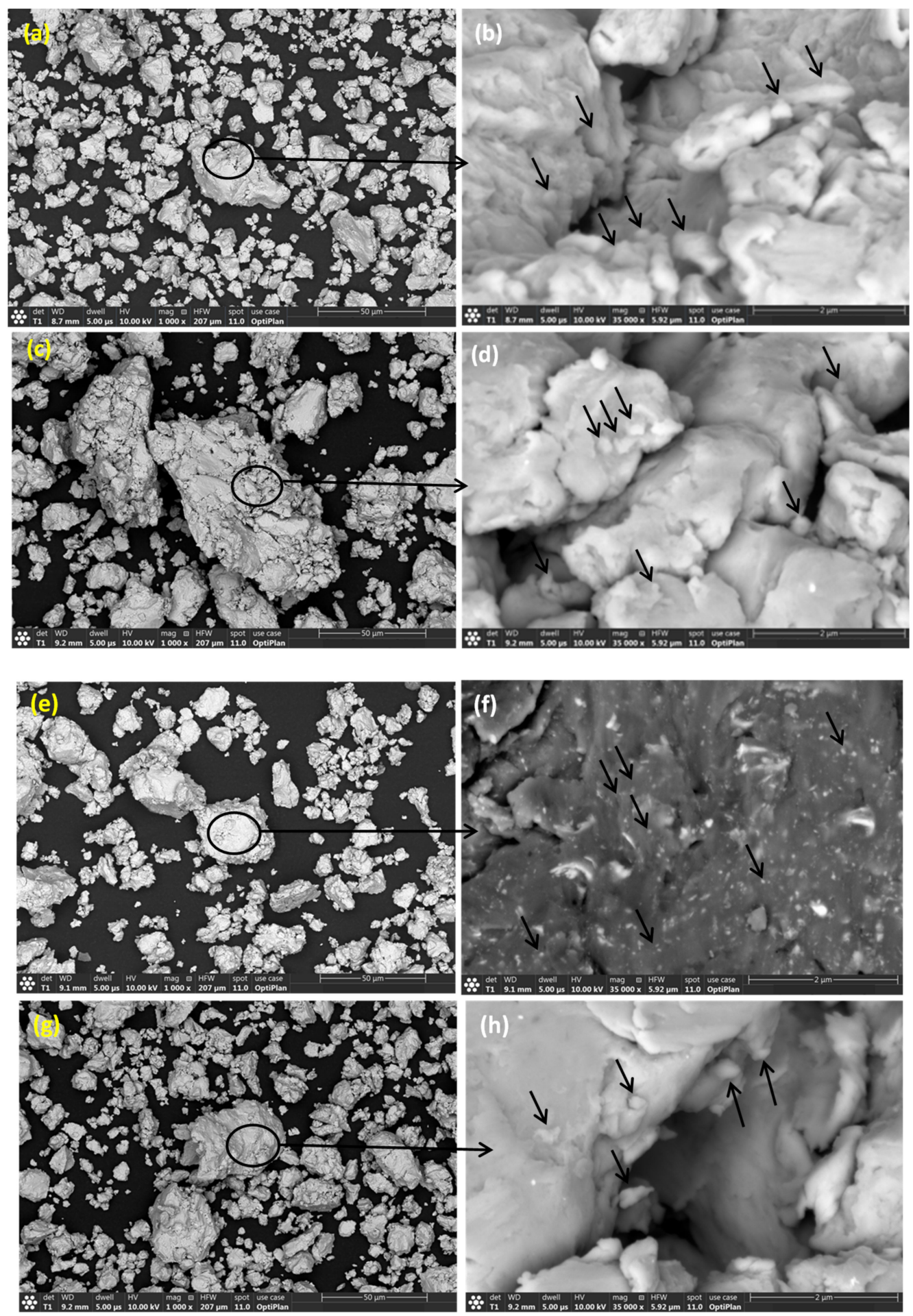

Figure 3. (a,c,e,g) BSE images of the morphology of the mAed BM0, BM1, BM2, and BM3 alloys, respectively; (b,d,f,h) high magnification BSE images of the circled region in $(\mathbf{a}, \mathbf{c}, \mathbf{e}, \mathbf{g})$, respectively.

The EDS analysis of the MAed BM0, BM1, BM2, and BM3 alloys are presented in Figure 4. Figure $4 a, c, e, g$ show the SE image of the selected regions for elemental mapping of BM0, BM1, BM2, and BM3 alloys, respectively. Figure $4 \mathrm{~b}, \mathrm{~d}, \mathrm{f}, \mathrm{h}$ display the overlay maps of the MAed BM0, BM1, BM2, and BM3 alloys, respectively. The overlay map in Figure 4b presents the Fe and Mn even dispersion in the MAed BM0 alloy. Figure $4 \mathrm{~d}$ reveals the uniform dispersion of $\mathrm{Fe}, \mathrm{Mn}$ and $\mathrm{Cu}$ in the MAed BM1 alloy. Figure $4 \mathrm{f}$ displays the dispersion of $\mathrm{Fe}, \mathrm{Mn}$, and $\mathrm{W}$ in the MAed BM2 alloy. Figure 4h shows the dispersion 
of Fe, Mn, and Co in the MAed BM3 alloy. The results presented in Figure 4 ascertain the development of a homogenous elemental dispersions and solid solution in all the developed alloys.
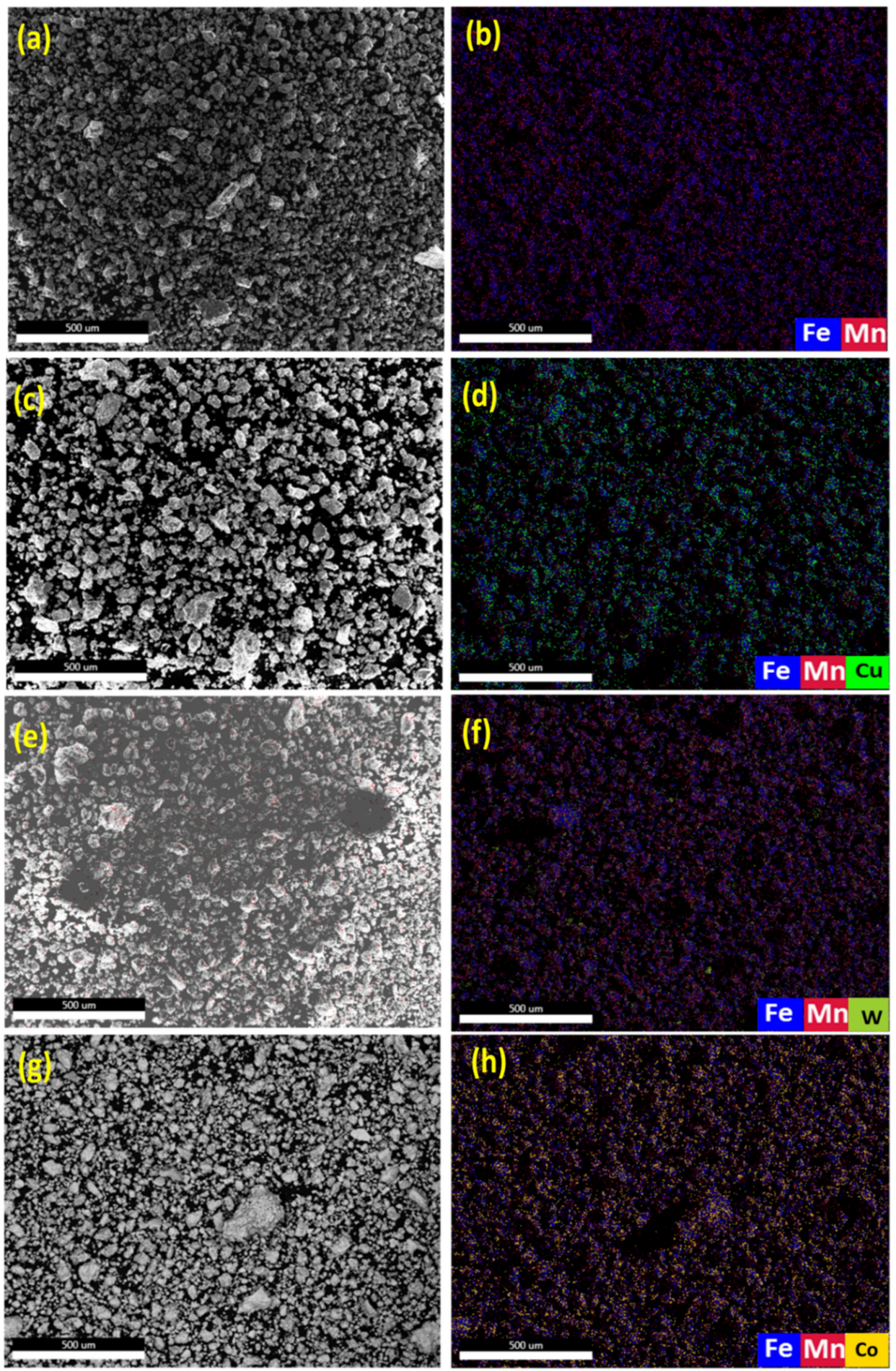

Figure 4. The results of EDS analysis of the MAed BM0, BM1, BM2, and BM3 alloys: (a,c,e,g) SE images of BM0, BM1, BM2, and BM3 alloys, respectively; (b,d,f,h) overlay maps of the same BM0, $\mathrm{BM} 1, \mathrm{BM} 2$, and BM3 alloys, respectively. 


\subsection{XRD Analyses of the Developed Fe-Mn, Fe-Mn-Cu, Fe-Mn-W, and Fe-Mn-Co Alloys Powders}

The XRD patterns obtained for BM0, BM1, BM2, and BM3 alloys powders are displayed in Figure 5. For BM0 alloy, the main identified phases were Fe and $\mathrm{Mn}$. With regard to BM1 alloy the same phases (Fe and Mn) were identified in addition to $\mathrm{Cu}$ phase. In similar manner, phases of Fe and $\mathrm{Mn}$ with the corresponding addition of $\mathrm{W}$ and Co were observed in BM2 and BM3 alloys. The characteristics of the observed phases for the developed alloys are displayed in Table 2. The crystallite size and lattice strain were calculated based on the highest peak intensity using X'Pert High Score Plus software according to Debye-Scherrer principles. Regarding Figure 5 and Table 2, the highest intensity peaks in BM0 alloy was $1177.34 \mathrm{cps}$ at $2 \theta$ of $44.6435 \mathrm{deg}$; for BM1 alloy the maximum peak intensity was $941.81 \mathrm{cps}$ at $2 \theta$ of $44.8965 \mathrm{deg}$; for BM2 alloy the highest peak intensity was $1074.74 \mathrm{cps}$ at $2 \theta$ of $44.6901 \mathrm{deg}$; and for BM3 alloy the maximum peak intensity was $884.87 \mathrm{cps}$ at $2 \theta$ of $40.3947 \mathrm{deg}$. The calculated crystallite size corresponding to these maximum peaks are $21.4 \mathrm{~nm}, 21.4 \mathrm{~nm}, 15.5 \mathrm{~nm}$, and $24.2 \mathrm{~nm}$ for BM0, BM1, BM2, and BM3 alloys, respectively. The obtained lattice strain corresponding to the highest peaks are $0.432,0.432,0.598$, and 0.425 for BM0, BM1, BM2, and BM3 alloys, respectively. These observations assured the effect of mechanical alloying on the reduction of the crystallite size ( $44 \mu \mathrm{m}$ to $21.4 \mathrm{~nm}$, for BM0 for example) and the increased lattice strain due to sever plastic deformation during ball milling as noted from the calculated lattice strain ( $0.432 \%$ for BM0, for example).

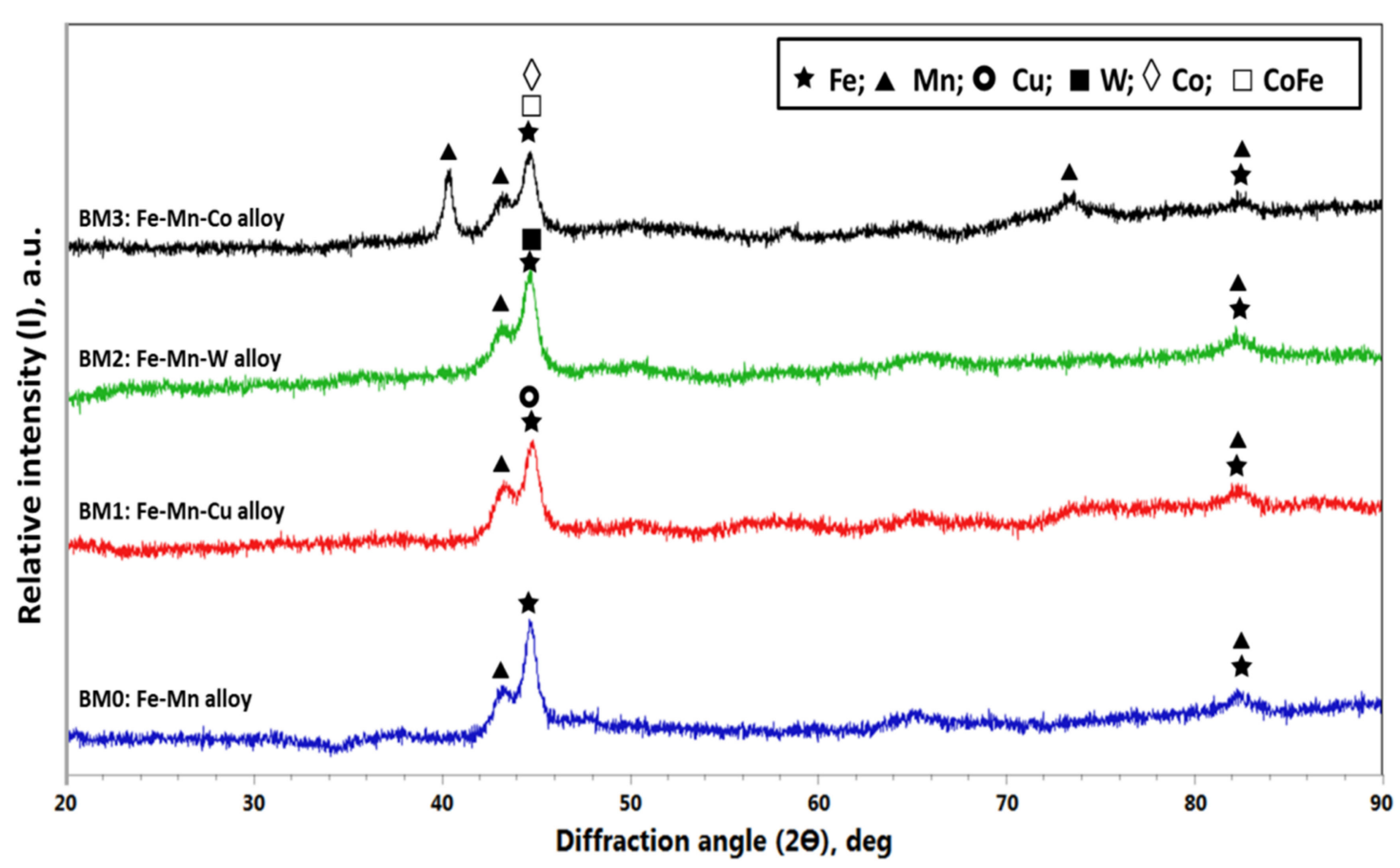

Figure 5. XRD results of MAed BM0, BM1, BM2, and BM3 alloys.

\subsection{HRTEM Analyses of Four Synthesized Fe-Mn, Fe-Mn-Cu, Fe-Mn-W, and Fe-Mn-Co Nanostructured Alloys}

The developed alloy powders were characterized by HRTEM and the same is illustrated in Figure 6. From several bright filed and dark field images of each sample, the crystal size was measured using ImageJ software and the average was reported. The average crystallite size of alloy powders was $24.6 \pm 3,22.3 \pm 5,19.5 \pm 2$, and $25.6 \pm 3 \mathrm{~nm}$ for BM0, BM1, BM2, and BM3 alloys, respectively. The inset of Figure $6 a, c, e, g$ show the selective area diffraction patterns of corresponding bright filed images. All SAED pattern exhibit the ring pattern conforming the nanostructured formation by the used methodology. Figure $6 \mathrm{~b}, \mathrm{~d}, \mathrm{f}, \mathrm{h}$ show the lattice fringe images of each alloy powder taken at high magnification. The presence of $\mathrm{Fe}, \mathrm{Mn}, \mathrm{Cu}, \mathrm{W}$, and Co lattice was observed based on the 
corresponding composition of each alloy. For instance, the HRTEM-EDS spectrum was taken for BM1 and BM 4 alloys which exhibited Fe-Mn-Cu and Fe-Mn-Co peaks for BM1 and BM3 alloys, respectively. With regard to the results obtained from XRD, FEG-HRSEM-EDS, and HRTEM-EDS, it was confirmed that the nanostructured BM0, BM1, BM2, and BM3 alloys were developed successfully using mechanical alloying technique with homogenous solid solutions.

Table 2. The characteristics of the observed phases in MAed BM0, BM1, BM2, and BM3 alloys.

\begin{tabular}{|c|c|c|c|c|c|c|c|}
\hline Alloy Code & $\begin{array}{l}\text { Observed } \\
\text { Phase }\end{array}$ & $\begin{array}{l}\text { Position } \\
2 \theta, \text { Deg }\end{array}$ & $\begin{array}{c}\text { Peak Height, } \\
\text { Cps }\end{array}$ & Code & Structure & $\begin{array}{c}\text { Crystal Size } \\
(\mathrm{nm})\end{array}$ & $\begin{array}{c}\text { Lattice } \\
\text { Strain (\%) }\end{array}$ \\
\hline \multirow{4}{*}{ BM0 } & \multirow{3}{*}{$\mathrm{Fe}$} & 44.6435 & 1177.34 & 01-085-1410 & Cubic & \multirow{4}{*}{21.4} & \multirow{4}{*}{0.432} \\
\hline & & 82.3443 & 104.51 & 01-085-1410 & Cubic & & \\
\hline & & 42.9402 & 277.57 & 00-001-1237 & Cubic & & \\
\hline & $\mathrm{Mn}$ & 82.3443 & 104.51 & 00-003-1014 & Cubic & & \\
\hline \multirow{5}{*}{ BM1 } & \multirow{2}{*}{$\mathrm{Fe}$} & 44.8965 & 941.81 & 01-087-0722 & Cubic & \multirow{5}{*}{21.4} & \multirow{5}{*}{0.432} \\
\hline & & 82.2603 & 92.06 & $01-087-0722$ & Cubic & & \\
\hline & \multirow{2}{*}{$\mathrm{Mn}$} & 43.3474 & 293.13 & 00-001-1234 & Cubic & & \\
\hline & & 82.2603 & 92.06 & 00-001-1234 & Cubic & & \\
\hline & $\mathrm{Cu}$ & 43.3474 & 293.13 & 01-089-2838 & Cubic & & \\
\hline \multirow{5}{*}{$\mathrm{BM} 2$} & \multirow{2}{*}{$\mathrm{Fe}$} & 44.6901 & 1074.74 & 01-087-0721 & Cubic & \multirow{5}{*}{15.5} & \multirow{5}{*}{0.598} \\
\hline & & 82.1962 & 213.56 & 01-087-0721 & Cubic & & \\
\hline & \multirow{2}{*}{$\mathrm{Mn}$} & 43.7106 & 212.34 & 00-001-1234 & Cubic & & \\
\hline & & 82.1962 & 213.56 & 00-001-1234 & Cubic & & \\
\hline & W & 44.6901 & 1074.74 & 01-088-2339 & Cubic & & \\
\hline \multirow{8}{*}{ BM3 } & \multirow{2}{*}{$\mathrm{Fe}$} & 44.7608 & 862.36 & 01-087-0722 & Cubic & \multirow{8}{*}{24.2} & \multirow{8}{*}{0.425} \\
\hline & & 82.6692 & 133.67 & 01-087-0722 & Cubic & & \\
\hline & Co & 44.7608 & 862.36 & 00-001-1254 & Cubic & & \\
\hline & $\mathrm{CoFe}$ & 44.7608 & 862.36 & 00-044-1433 & Cubic & & \\
\hline & \multirow{4}{*}{$\mathrm{Mn}$} & 40.3947 & 884.87 & 00-032-0637 & Cubic & & \\
\hline & & 42.9173 & 161.46 & 00-032-0637 & Cubic & & \\
\hline & & 73.5610 & 96.49 & 00-032-0637 & Cubic & & \\
\hline & & 82.6692 & 133.67 & 00-032-0637 & Cubic & & \\
\hline
\end{tabular}

\subsection{Compressibility of $\mathrm{Fe}-\mathrm{Mn}$, Fe-Mn-Cu, Fe-Mn-W, and Fe-Mn-Co Nanostructured Alloys}

The compressibility of MAed BM0, BM1, BM2, and BM3 alloys was investigated for the purpose of examining the densification behavior of these alloys. The experiments were conducted at different load up to $1100 \mathrm{MPa}$. The compressibility of the processed alloys was examined in the as-milled (BM0, BM1, BM2, and BM3) condition and after applying stress relief treatment $\left(150^{\circ} \mathrm{C} / 1 \mathrm{~h}\right)$ to the same alloys (codes for stress relieved samples: BM0-S, BM1-S, BM2-S, and BM3-S). The densification behavior of the same alloys in the as-milled and stress relieved conditions was further studied empirically to identify the optimum model to predict the density of these alloys [31]. A number of linear and non-linear models were applied in the present study for predicting the alloy compressibility. The density of the green samples prepared at $1100 \mathrm{MPa}$ for the as milled and stress relieved samples are listed in Table 3.

The attained relative density of the as milled BM0, BM1, BM2, and BM3 alloys was $72.89 \%, 71.64 \%, 72.38 \%$, and $72.03 \%$, respectively. After applying the stress relief treatment, the relative density BM0-S, BM1-S, BM2-S, and BM3-S alloys samples was observed to increase to $75.23 \%, 77.10 \%, 72.65 \%$, and $72.86 \%$, respectively. The enhanced relative density as a result of applying stress relief treatment is related to the decreased resistance to powder compressibility due to the reduced lattice strain and diminished strain hardening of the heat-treated powders. However, the observed improvements in relative density of the samples studied are limited due to low temperature and short time applied for heat treatment. This heat treatment was proposed to reduce lattice strain with minimizing the probability of grain growth and structural changes. 

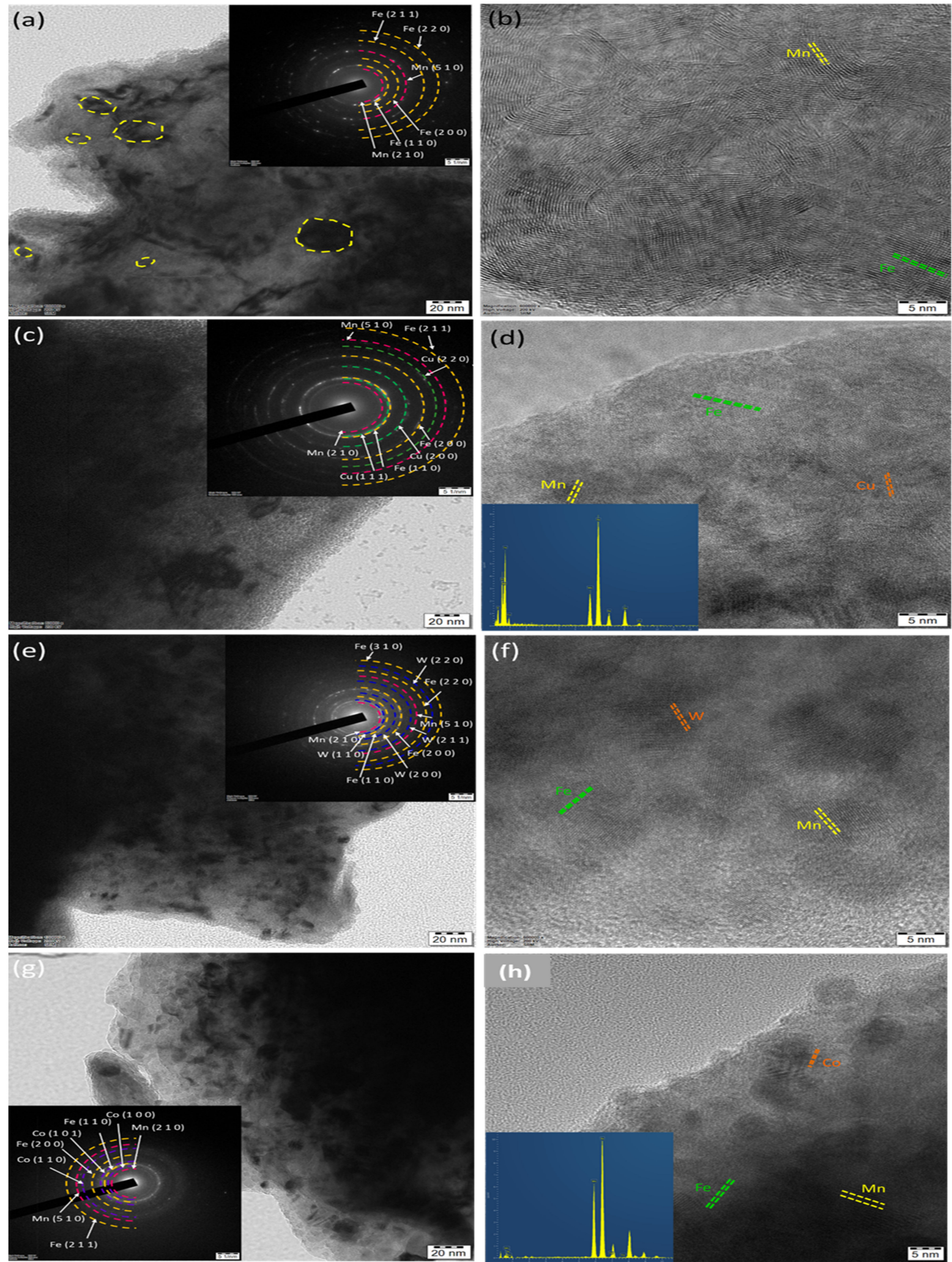

Figure 6. HRTEM analyses of MAed BM0, BM1, BM2, and BM3 nanocrystallite alloy powders: (a) bright filed image (BFI) of BM0; (b) lattice fringe image (LFI) of BM0; (c) BFI of BM1; (d) LFI of BM1; € BFI of BM2; (e) LFI of BM2; (f) BFI of BM3; and (g) LFI of BM3. Inset of $(\mathbf{a}, \mathbf{c}, \mathbf{e}, \mathbf{g})$ showing the corresponding SAED patterns; inset of $(\mathbf{d}, \mathbf{h})$ showing the corresponding EDS. 
Table 3. The density of the green samples prepared at $1100 \mathrm{MPa}$ for the as milled and stress relieved samples.

\begin{tabular}{|c|c|c|c|}
\hline Alloy Code & $\begin{array}{c}\text { Theoretical } \\
\text { Density }\left(\mathrm{g} / \mathrm{cm}^{3}\right)\end{array}$ & $\begin{array}{l}\text { Green Density } \\
\left(\mathrm{g} / \mathrm{cm}^{3}\right)\end{array}$ & $\begin{array}{c}\text { Relative } \\
\text { Density (\%) }\end{array}$ \\
\hline BM0 & 7.73 & 5.63 & 72.90 \\
\hline BM0-S & 7.73 & 5.81 & 75.23 \\
\hline BM1 & 7.77 & 5.77 & 71.64 \\
\hline BM1-S & 7.77 & 5.99 & 77.10 \\
\hline BM2 & 8.19 & 5.93 & 72.38 \\
\hline BM2-S & 8.19 & 5.95 & 72.65 \\
\hline BM3 & 7.77 & 5.59 & 72.03 \\
\hline BM3-S & 7.77 & 5.66 & 72.86 \\
\hline
\end{tabular}

The microstructure and elemental dispersion in BM0, BM1, BM2, and BM3 green samples are displayed in Figure 7. Figure 7a-c display the SE image, overlay elemental dispersion and EDS composition analysis, respectively for BM0 compacted sample. Figure $7 \mathrm{~d}-\mathrm{f}$ reveal the SE image, overlay map and EDS results, respectively for BM1 green sample. Figure $7 \mathrm{~g}-\mathrm{i}$ show the SE image, overlay elemental distribution and EDS analysis, respectively for BM2 compressed sample. Figure 7j-1 present the SE image, overlap elemental dispersion and EDS results, respectively for BM3 green sample. The EDS results of elemental mapping represented in Figure 7 confirmed the formation of homogenous solid solution of $\mathrm{Mn}$ in $\mathrm{Fe}$ in the case of BM0 compacted sample, and uniform dispersion of $\mathrm{Cu}, \mathrm{W}$, and $\mathrm{Co}$ in the matrix phase corresponding to BM1, BM2, and BM3 green samples, respectively.

Figure $8 \mathrm{a}, \mathrm{c}, \mathrm{e}, \mathrm{f}$ reveal SE images at low magnifications displaying the overview of BM0, BM1, BM2, and BM3 green sample, respectively. Figure 8b,d,g,h show SE images at high magnifications of BM0, BM1, BM2, and BM3 compacted sample, respectively. The arrows refer to the voids present in the green compact while the circled regions refer to the coalescence of the particle, as a result of compaction process. The voids remained without complete welding/coalescence of powders due to the high lattice strain and strain hardening accompanying the MA process, which reduced the compressibility of the MAed powders.

Figure 9 shows the compressibility curves obtained experimentally for the alloys under investigation in the as-milled and stress relieved conditions. The densification behavior of BM0, BM0-S, BM1, BM1-S, BM2, BM2-S, BM3, and BM3-S samples are almost similar with a notable improved compressibility response for the stress relieved samples in BM0 and BM1 samples, as illustrated in Figure 9a,b. Increasing the compaction load resulted in a considerable increase in the relative density of synthesized alloys. The compressibility behavior in Figure 9 exhibited three steps of compaction. Firstly, a rapid increase in the alloy density in the range of 25-100 MPa due to the reordering of powder particles, which resulted in reducing the voids among these powders and decreasing the powders volume with achieving approximately 50\% relative density for BM1-S alloy, for instance. Secondly, a further increase in the relative density was recorded in the range of 100-200 MPa. The major mechanism in this second step is the powder deformation, which increased the powders contact and reduced the volume of voids. This mechanism results in reducing the volume of the compacted sample and consequently an additional increase in the sample relative density to $53 \%$ was attained for BM1-S sample, as an example. The curve in the second step was noted to display a lower slope as compared to step one. Finally, in the range of 200-1100 MPa, the curve exhibited a further increase in relative density and the maximum value (77\% for BM1-S alloy) was attained at $1100 \mathrm{MPa}$; however, the slope of the curve in this phase is lesser than that in the second step. The governing mechanism in the third stage is the powders impingement under the applied load. From Table 3 and Figure 9a,b it was noticed that the relative density of BM0 and BM1 alloys were enhanced by applying stress relief treatment (BM0-S and BM1-S samples). Heating the processed powders resulted in 
improving the powder compressibility, which was attributed to the effect of stress relief treatment on reducing the lattice strain and increasing the deformability of powders that led to reduced level of voids and increased contact among powder particles. On the other hand, for BM2 and BM3 alloys the effect of stress relief treatment was not significant. When adding $\mathrm{W}$ (BM2) or Co (BM3), the temperature and/or the time of the stress relief treatment should be increased for effective stress recovery to display significant effect on the compressibility of these alloys.

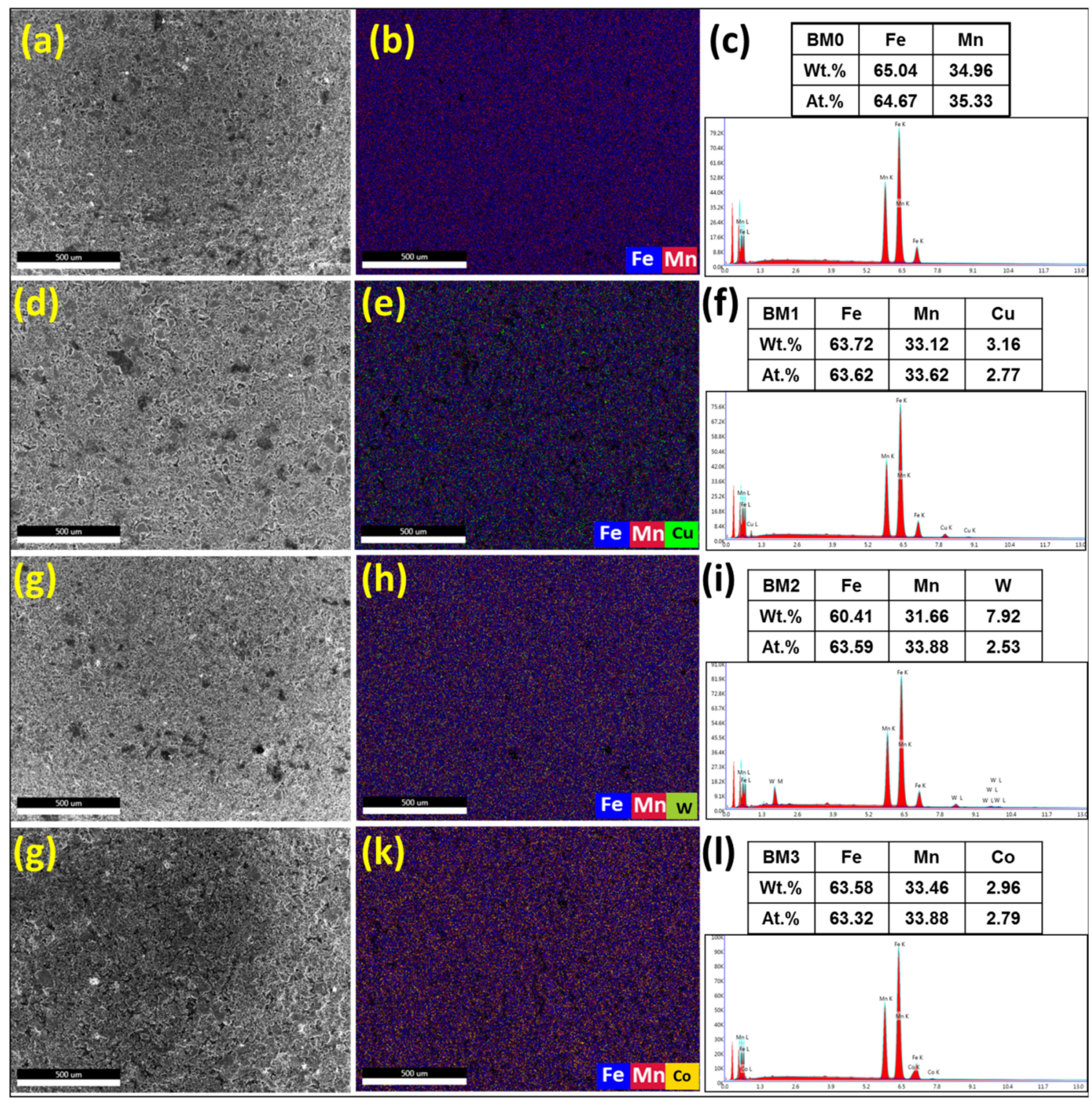

Figure 7. Secondary electron images, overlay elemental dispersion and EDS composition analysis results of the compacted samples: $(\mathbf{a}-\mathbf{c})$ the results for BM0 alloy; $(\mathbf{d}-\mathbf{f})$ the results for BM1 alloy; $(\mathbf{g}-\mathbf{i})$ the results for BM2 alloy; and (j-1) the results for BM3 alloy. 


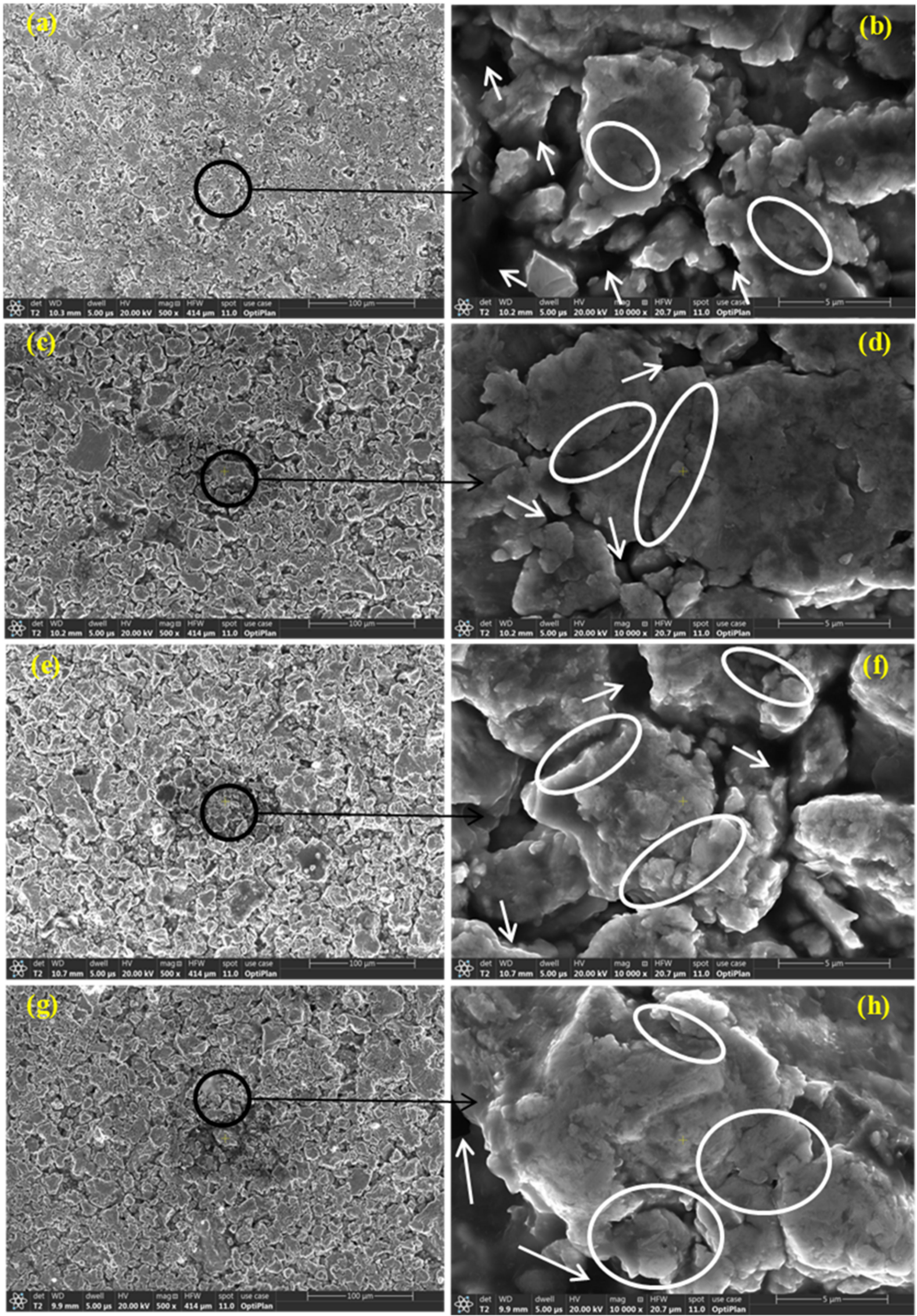

Figure 8. Secondary electron images at low and high magnifications displaying the overview of the green samples: $(\mathbf{a}, \mathbf{b})$ BM0 alloy; (c,d) BM1 alloy; (e,f) BM2 alloy; and (g,h) BM3 alloy. 

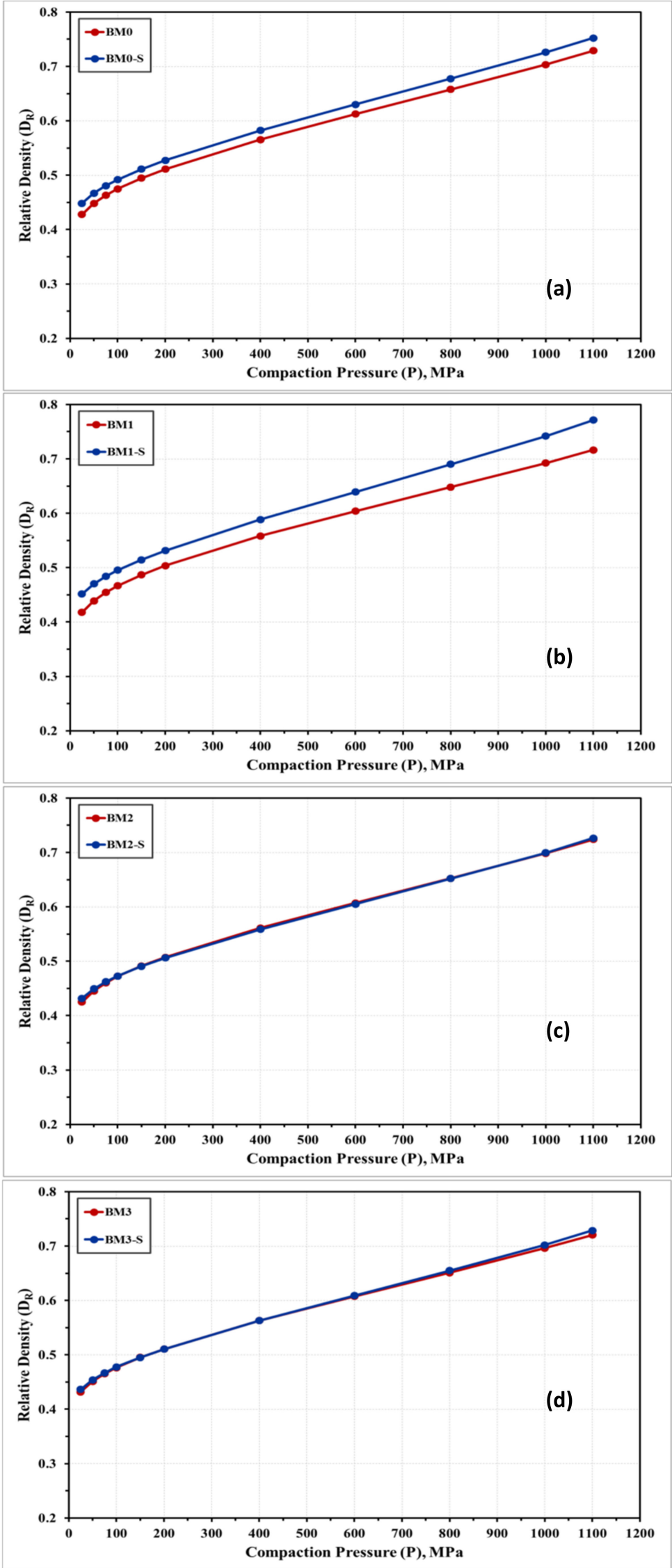

Figure 9. Relative density of (a) BM0; (b) BM1; (c) BM2; and (d) BM3 samples in the as-milled vs. stress relieved conditions. 
The compressibility behavior of the Fe-Mn, Fe-Mn-Cu, Fe-Mn-W, and Fe-Mn-Co alloys was additionally examined empirically by a number of linear and non-linear models. These models correlate the attained density with the loads applied during compaction. Based on the obtained experimental results, these models will be used for expecting the green density of the produced nanocrystalline alloys in the as-milled and stress relieved conditions. The models applied in the present study are described below where the linear models are presented in Equations (1) through (5) while the nonlinear ones are displayed in Equations (6) through (8).

Balshin's model [32]:

$$
\frac{1}{D_{R}}=K \ln P+A
$$

Heckel's model [33]:

$$
\ln \left(\frac{1}{1-D_{R}}\right)=K P+A
$$

Ge's model [34]:

$$
\log \left[\ln \frac{1}{1-D_{R}}\right]=K \log P+A
$$

Panelli and Ambrosio Filho's model [35]:

$$
\ln \left(\frac{1}{1-D_{R}}\right)=K \sqrt{P}+A
$$

Kawakita's model [36]:

$$
\frac{D_{R}}{D_{R}-D_{o}}=\frac{K}{P}+A
$$

Shapiro's model [37]:

$$
\ln \left(1-D_{R}\right)=\ln \left(1-D_{o}\right)-C P-B \sqrt{P}+A
$$

Cooper and Eaton's model [38]:

$$
\frac{D_{R}-D_{o}}{D_{R}\left(1-D_{o}\right)}=a_{1} \exp \left(\frac{-k_{1}}{P}\right)+a_{2} \exp \left(\frac{-k_{2}}{P}\right)
$$

Van Der Zwan and Siskens's model [39]:

$$
\frac{D_{R}-D_{o}}{\left(1-D_{o}\right)}=\operatorname{aexp}\left(\frac{-k}{P}\right)
$$

With regard to the above-listed models: " $P$ " is the applied load; " $D_{R}$ " is relative density; " $D_{o}$ " is the relative apparent density; and $A, a, a_{1}, a_{2}, K, k_{1}$, and $k_{2}$ are specific factors for each model that can be estimated from the data fitting of the compressibility curves. Figures 10 and 11 represent the compressibility behavior of BM0, BM1, BM2, and BM3 alloys in the as-milled and stress relieved conditions, respectively. Figures 10a and 11a display the compressibility of the as-milled (BM0, BM1, BM2, and BM3) and stress relieved (BM0-S, BM1-S, BM2-S, and BM1-S) samples based on the experimentations performed in the present study. Figure $10 \mathrm{~b}-\mathrm{i}$ show the compressibility behavior of the as-milled samples based on models 1 through 8, respectively, while Figure 11b-i display the compaction curves of the stress-relieved samples according to equations 1 through 8 , respectively. The estimated factors related to each model based on the experimentations performed in the current study are presented in Table 4 . The compressibility results displayed in Table 4 and Figures 10 and 11 illustrate that the general behavior of BM0/BM0-S, BM1/BM1-S, BM2/BM2-S, and BM3/BM3-S alloys are almost similar with the exception of the positive influence of the stress-relief treatment on compressibility of BM0-S and BM1-S samples. From the analysis of these results, the optimum models for predicating the compressibility 
of the alloys under study in the as-milled and stress-relieved conditions are Equation (2) (linear) and Equation (6) (non-linear). The application of Equation (2) and Equation (6) revealed the highest $\mathrm{R}^{2}$-values of 0.9967 and 0.9974 , respectively (in the case of BM0 alloy, for instance). In contrast, Equation (5) (linear) and Equation (8) (non-linear) exhibited the lowest $\mathrm{R}^{2}$-values of 0.8974 and 0.9230 , respectively (for BM0 alloy, for example). Consequently, Heckel's linear model presented in Equation (2) and the Shapiro's non-linear model displayed in Equation (6) are the optimum compaction models for predicting the compressibility behavior for nanostructured Fe-Mn, Fe-Mn-Cu, Fe-Mn-W, and Fe-Mn-Co alloys in the as-milled and stress-relieved conditions.
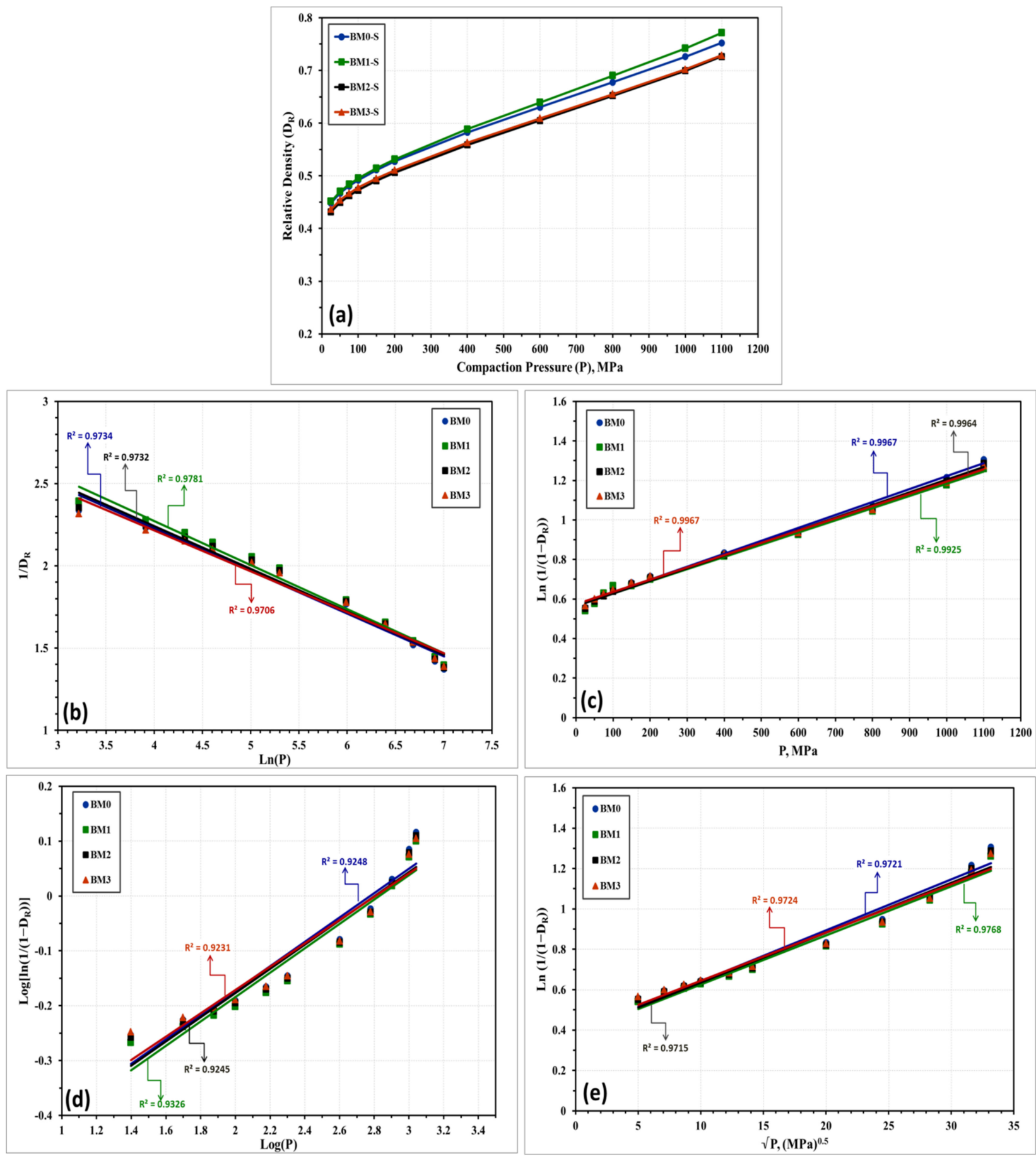

Figure 10. Cont. 

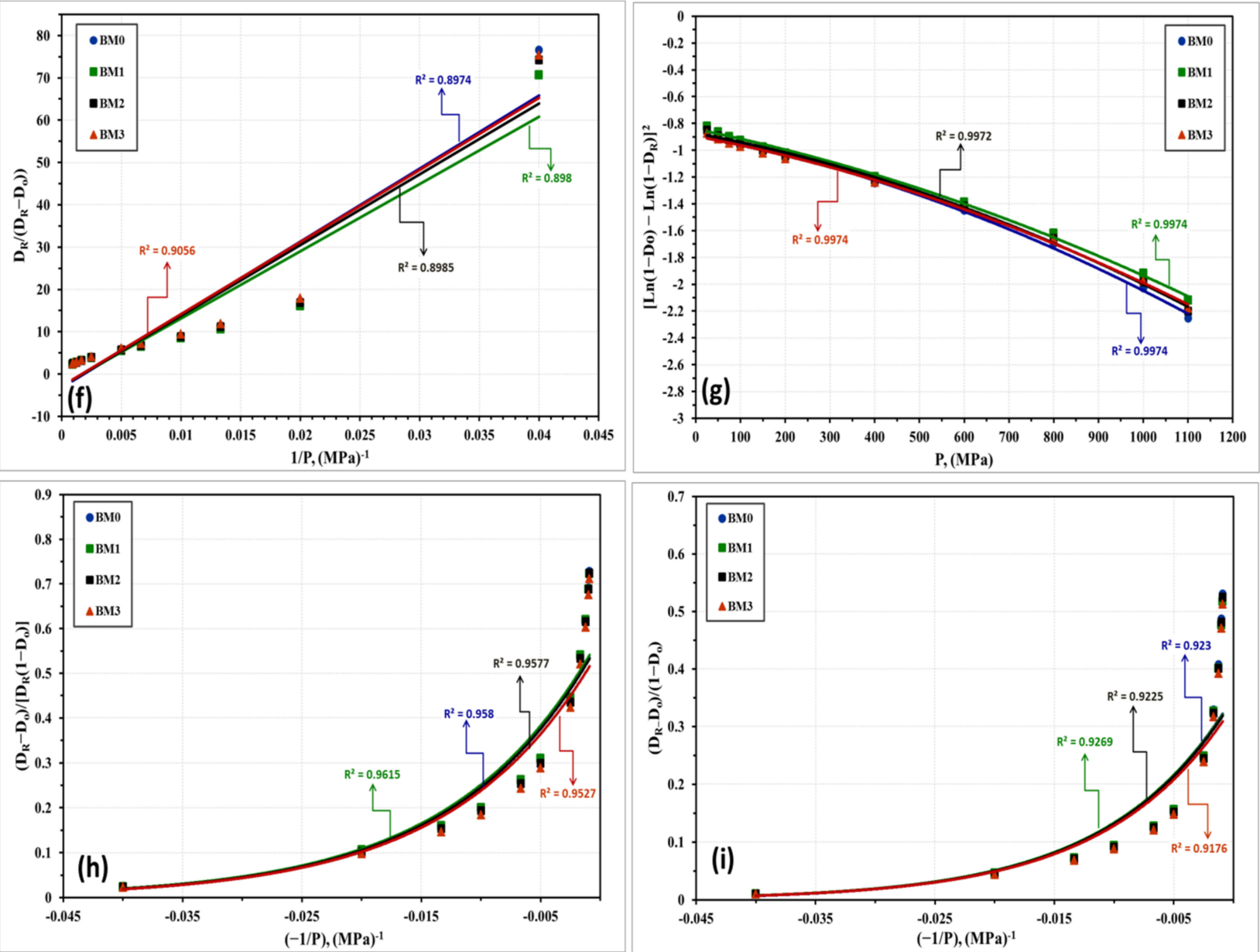

Figure 10. Compressibility results of the as-milled BM0, BM1, BM2, and BM3 alloy samples obtained from: (a) compressibility experiments conducted on these alloys. (b-i) are the compressibility results obtained empirically from applying models (1) through (8), one-to-one. 

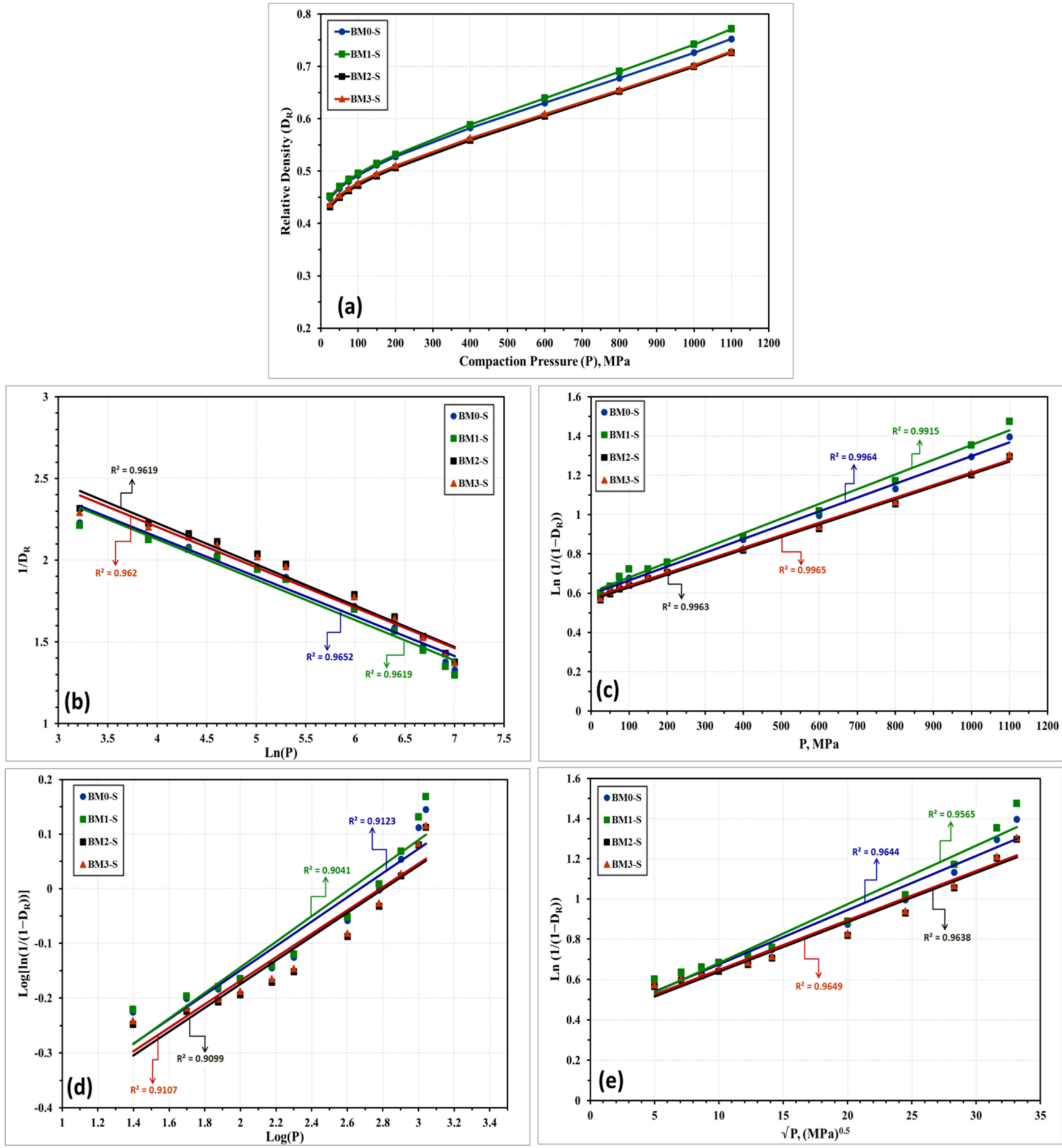

Figure 11. Cont. 

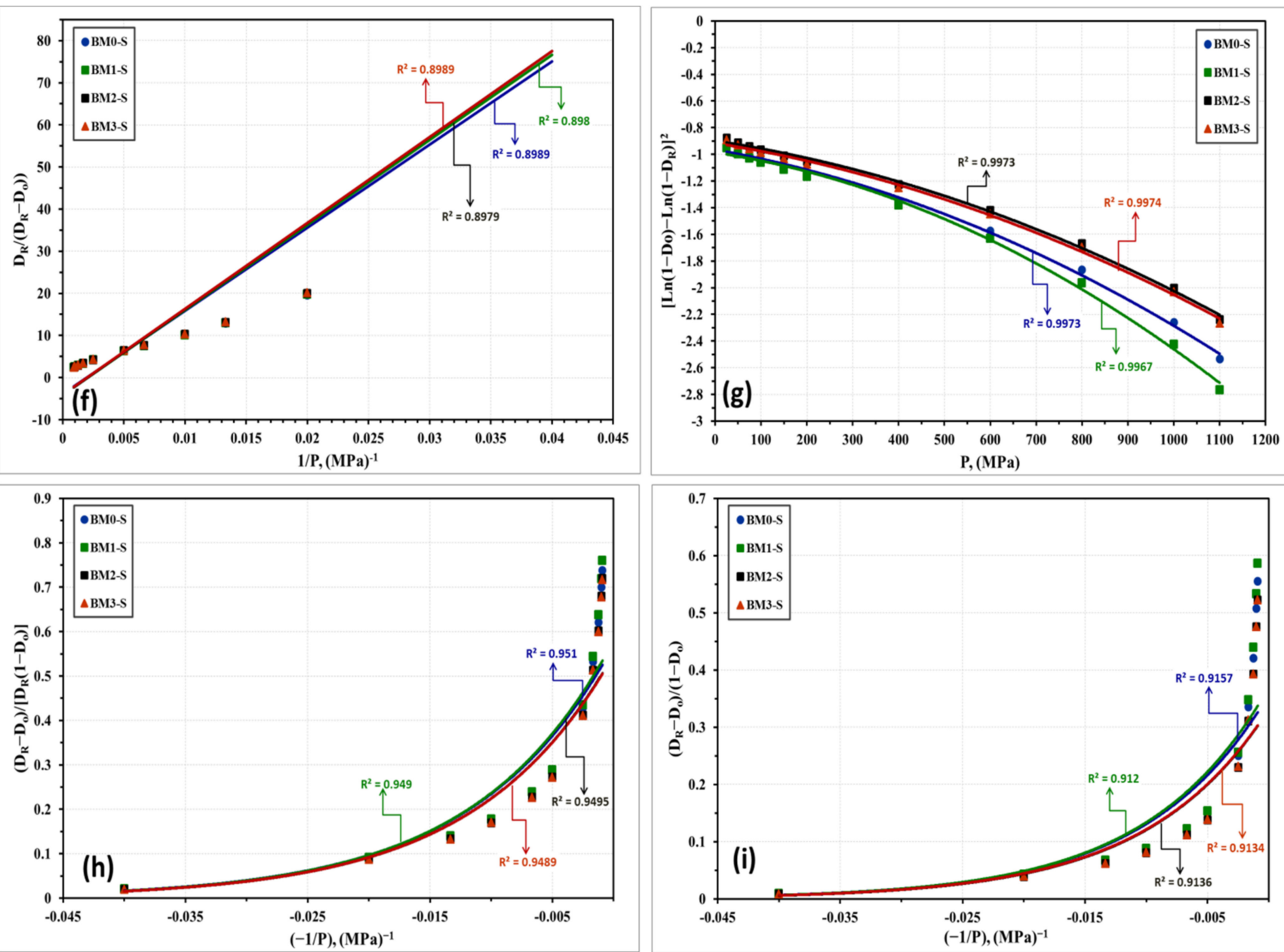

Figure 11. Compressibility results of the stress-relieved samples BM0-S, BM1-S, BM2-S, and BM3-S alloy samples obtained from: (a) compressibility experiments conducted on these alloys. (b-i) the compressibility results obtained empirically from applying models $(1)$ through (8), one-to-one.

Table 4. The estimated factors related to the models applied on the alloys investigated in the present study.

\begin{tabular}{|c|c|c|c|c|c|c|c|c|c|}
\hline \multirow{2}{*}{$\begin{array}{c}\text { Applied } \\
\text { Model }\end{array}$} & \multirow{2}{*}{ Factor } & \multicolumn{8}{|c|}{ Alloy Code } \\
\hline & & BM0 & BM0-S & BM1 & BM1-S & BM2 & BM2-S & BM3 & BM3-S \\
\hline \multirow{3}{*}{ Balshin [32] } & $\mathrm{A}$ & 3.2633 & 3.1128 & 3.3414 & 3.1163 & 3.2822 & 3.2384 & 3.2107 & 3.1931 \\
\hline & $\mathrm{K}$ & -0.2950 & -0.2430 & -0.2670 & -0.2470 & -0.2600 & -0.2530 & -0.2490 & -0.247 \\
\hline & $\mathrm{R}^{2}$ & 0.9734 & 0.9652 & 0.9781 & 0.9619 & 0.9732 & 0.9619 & 0.9706 & 0.9620 \\
\hline \multirow{3}{*}{ Heckel [33] } & A & 0.5685 & 0.5961 & 0.5665 & 0.6054 & 0.5639 & 0.5659 & 0.5751 & 0.5749 \\
\hline & $\mathrm{K}$ & 0.0007 & 0.0007 & 0.0006 & 0.0007 & 0.0006 & 0.0006 & 0.0006 & 0.0006 \\
\hline & $\mathrm{R}^{2}$ & 0.9967 & 0.9964 & 0.9925 & 0.9915 & 0.9964 & 0.9963 & 0.9967 & 0.9965 \\
\hline \multirow{3}{*}{ Ge [34] } & A & -0.6171 & -0.5949 & -0.6280 & -0.6099 & -0.6176 & -0.6072 & -0.5969 & -0.5972 \\
\hline & $\mathrm{K}$ & 0.2223 & 0.2228 & 0.2220 & 0.2332 & 0.2204 & 0.2165 & 0.2128 & 0.2144 \\
\hline & $\mathrm{R}^{2}$ & 0.9248 & 0.9123 & 0.9326 & 0.9041 & 0.9245 & 0.9099 & 0.9231 & 0.9107 \\
\hline Panelli and & A & 0.3895 & 0.4057 & 0.3825 & 0.3900 & 0.3885 & 0.3924 & 0.4050 & 0.4013 \\
\hline Ambrosio & $\mathrm{K}$ & 0.0252 & 0.0270 & 0.0243 & 0.0292 & 0.0247 & 0.0246 & 0.0239 & 0.0246 \\
\hline Filho's [35] & $\mathrm{R}^{2}$ & 0.9721 & 0.9644 & 0.9768 & 0.9565 & 0.9715 & 0.9638 & 0.9724 & 0.9649 \\
\hline \multirow{3}{*}{ Kawakita [36] } & A & -3.1733 & -3.9202 & -2.7487 & -4.1445 & -2.9476 & -4.1586 & -2.8135 & -4.0914 \\
\hline & $\mathrm{K}$ & 1725 & 1976.1 & 1590.6 & 2019.6 & 1671.3 & 2041.7 & 1701.7 & 2040.8 \\
\hline & $\mathrm{R}^{2}$ & 0.8974 & 0.8989 & 0.8980 & 0.8980 & 0.8985 & 0.8979 & 0.9056 & 0.8989 \\
\hline \multirow{4}{*}{ Shapiro [37] } & $\mathrm{A}$ & -0.8826 & -0.9652 & -0.8428 & -0.9865 & -0.8725 & -0.8984 & -0.8951 & -0.9154 \\
\hline & B & $-6 \times 10^{-4}$ & $-6 \times 10^{-4}$ & $-7 \times 10^{-4}$ & $-5 \times 10^{-4}$ & $-6 \times 10^{-4}$ & $-5 \times 10^{-4}$ & $-6 \times 10^{-4}$ & $-5 \times 10^{-4}$ \\
\hline & $\mathrm{C}$ & $-5 \times 10^{-7}$ & $-7 \times 10^{-7}$ & $-4 \times 10^{-7}$ & $-1 \times 10^{-6}$ & $-5 \times 10^{-7}$ & $-6 \times 10^{-7}$ & $-5 \times 10^{-7}$ & $-6 \times 10^{-7}$ \\
\hline & $\mathrm{R}^{2}$ & 0.9974 & 0.9973 & 0.9974 & 0.9967 & 0.9972 & 0.9973 & 0.9974 & 0.9974 \\
\hline
\end{tabular}


Table 4. Cont.

\begin{tabular}{|c|c|c|c|c|c|c|c|c|c|}
\hline \multirow{2}{*}{$\begin{array}{c}\text { Applied } \\
\text { Model }\end{array}$} & \multirow{2}{*}{ Factor } & \multicolumn{8}{|c|}{ Alloy Code } \\
\hline & & BM0 & BM0-S & BM1 & BM1-S & BM2 & BM2-S & BM3 & BM3-S \\
\hline \multirow{5}{*}{$\begin{array}{c}\text { Cooper and } \\
\text { Eaton [38] }\end{array}$} & $a_{1}$ & 0.4194 & 0.4083 & 0.4291 & 0.4115 & 0.4165 & 0.3899 & 0.7308 & 0.3868 \\
\hline & $\mathrm{a}_{2}$ & 0.7248 & 0.7866 & 0.6836 & 0.8324 & 0.7330 & 0.7959 & 0.4034 & 0.7886 \\
\hline & $\mathrm{k}_{1}$ & 79.6217 & 86.1326 & 77.3395 & 86.8809 & 77.8816 & 86.1326 & 909.090 & 85.470 \\
\hline & $\mathrm{k}_{2}$ & 884.955 & 909.091 & 869.565 & 917.4312 & 900.9 & 925.925 & 80.9716 & 917.43 \\
\hline & $\mathrm{R}^{2}$ & 0.9580 & 0.9510 & 0.9615 & 0.9490 & 0.9577 & 0.9495 & 0.9527 & 0.9489 \\
\hline Van Der & A & 0.3524 & 0.3574 & 0.3505 & 0.3698 & 0.3477 & 0.3316 & 0.3370 & 0.3324 \\
\hline Zwan and & $\mathrm{K}$ & 97.9340 & 100.2600 & 96.5250 & 101.6200 & 97.0280 & 100.9900 & 96.3640 & 100.5400 \\
\hline Siskens [39] & $\mathrm{R}^{2}$ & 0.9230 & 0.9157 & 0.9269 & 0.9120 & 0.9225 & 0.9136 & 0.9176 & 0.9134 \\
\hline
\end{tabular}

\section{Conclusions}

- The nanostructured Fe-Mn (BM0), Fe-Mn-Cu (BM1), Fe-Mn-W (BM2), and Fe-Mn-Co (BM3) alloys were successfully synthesized in the present study using mechanical alloying.

- The XRD, SEM-EDS, and HRTEM results confirmed the formation of homogenous solid solutions with an even elemental dispersion of alloys with the attainment of nanostructured alloys.

- The attained relative density of the as-milled BM0, BM1, BM2, and BM3 alloys at $1100 \mathrm{MPa}$ was $72.90 \%, 71.64 \%, 72.38 \%$, and $72.03 \%$, respectively. After applying the stress relief treatment, the density was observed to increase to $75.23 \%, 77.10 \%, 72.65 \%$, and $72.86 \%$ for BM0-S, BM1-S, BM2-S, and BM30S samples at $1100 \mathrm{MPa}$, respectively.

- The optimum models for predicating the compressibility of the alloys under study in the as-milled and stress-relieved conditions were Heckel's linear model and Shapiro's non-linear model which revealed the highest R2-values of 0.9967 and 0.9974 , respectively (in the case of BM0 alloy for instance).

Author Contributions: Conceptualization, H.R.A. and S.S.; methodology, H.R.A. and S.S.; formal analysis, H.R.A. and S.S.; investigation, H.R.A.; data curation, A.S.A.; writing-original draft preparation, H.R.A.; writing-review and editing, H.R.A., S.S. and A.S.A. All authors have read and agreed to the published version of the manuscript.

Funding: This research was funded by Qassim University, represented by the Deanship of Scientific Research, grant number (5583-qec-2019-2-2-I).

Data Availability Statement: The experimental datasets obtained from this research work and then the analyzed results during the current study are available from the corresponding author on reasonable request.

Acknowledgments: The authors gratefully acknowledge Qassim University, represented by the Deanship of Scientific Research, on the financial support for this research under the number (5583qec-2019-2-2-I) during the academic year $1440 \mathrm{AH} / 2019 \mathrm{AD}$.

Conflicts of Interest: The authors declare no conflict of interest.

\section{References}

1. Hermawan, H. Updates on the research and development of absorbable metals for biomedical applications. Prog. Biomater. 2018, 7, 93-110. [CrossRef] [PubMed]

2. Lin, W.; Qin, L.; Qi, H.; Zhang, D.; Zhang, G.; Gao, R.; Qiu, H.; Xia, Y.; Cao, P.; Wang, X. Long-term in vivo corrosion behavior, biocompatibility and bioresorption mechanism of a bioresorbable nitrided iron scaffold. Acta Biomater. 2017, 54, 454-468. [CrossRef] [PubMed]

3. Kraus, T.; Moszner, F.; Fischerauer, S.; Fiedler, M.; Martinelli, E.; Eichler, J.; Witte, F.; Willbold, E.; Schinhammer, M.; Meischel, M. Biodegradable Fe-based alloys for use in osteosynthesis: Outcome of an in vivo study after 52 weeks. Acta Biomater. 2014, 10, 3346-3353. [CrossRef] [PubMed]

4. Drynda, A.; Hassel, T.; Bach, F.W.; Peuster, M. In vitro and in vivo corrosion properties of new iron-manganese alloys designed for cardiovascular applications. J. Biomed. Mater. Res. Part B Appl. Biomater. 2015, 103, 649-660. [CrossRef] [PubMed]

5. Dehestani, M.; Adolfsson, E.; Stanciu, L.A. Mechanical properties and corrosion behavior of powder metallurgy ironhydroxyapatite composites for biodegradable implant applications. Mater. Des. 2016, 109, 556-569. [CrossRef] 
6. Vojtěch, D.; Kubasek, J.; Capek, J.; Michalcova, A.; Pospíšilová, I. Corrosion and mechanical behavior of biodegradable metallic biomaterials. Solid State Phenom. 2015, 227, 431-434. [CrossRef]

7. Ali, S.; Rani, A.M.A.; Baig, Z.; Ahmed, S.W.; Hussain, G.; Subramaniam, K.; Hastuty, S.; Rao, T.V. Biocompatibility and corrosion resistance of metallic biomaterials. Corros. Rev. 2020, 38, 381-402. [CrossRef]

8. Bormann, T.; Mai, P.T.; Gibmeier, J.; Sonntag, R.; Müller, U.; Kretzer, J.P. Corrosion behavior of surface-treated metallic implant materials. Materials 2020, 13, 2011. [CrossRef]

9. Schinhammer, M.; Steiger, P.; Moszner, F.; Löffler, J.F.; Uggowitzer, P.J. Degradation performance of biodegradable FeMnC (Pd) alloys. Mater. Sci. Eng. C 2013, 33, 1882-1893. [CrossRef]

10. Hufenbach, J.; Wendrock, H.; Kochta, F.; Kühn, U.; Gebert, A. Novel biodegradable Fe-Mn-CS alloy with superior mechanical and corrosion properties. Mater. Lett. 2017, 186, 330-333. [CrossRef]

11. Liu, B.; Zheng, Y.F.; Ruan, L. In vitro investigation of Fe30Mn6Si shape memory alloy as potential biodegradable metallic material. Mater. Lett. 2011, 65, 540-543. [CrossRef]

12. Hermawan, H.; Dubé, D.; Mantovani, D. Degradable metallic biomaterials: Design and development of Fe-Mn alloys for stents. J. Biomed. Mater. Res. Part A 2010, 93A, 1-11. [CrossRef]

13. Bagha, P.S.; Khakbiz, M.; Sheibani, S.; Hermawan, H. Design and characterization of nano and bimodal structured biodegradable Fe-Mn-Ag alloy with accelerated corrosion rate. J. Alloys Compd. 2018, 767, 955-965. [CrossRef]

14. Sotoudehbagha, P.; Sheibani, S.; Khakbiz, M.; Ebrahimi-Barough, S.; Hermawan, H. Novel antibacterial biodegradable Fe-Mn-Ag alloys produced by mechanical alloying. Mater. Sci. Eng. C 2018, 88, 88-94. [CrossRef]

15. Bagha, P.S.; Khakbiz, M.; Safaie, N.; Sheibani, S.; Ebrahimi-Barough, S. Effect of high energy ball milling on the properties of biodegradable nanostructured Fe-35 wt.\% Mn alloy. J. Alloys Compd. 2018, 768, 166-175. [CrossRef]

16. Safaie, N.; Khakbiz, M.; Sheibani, S.; Bagha, P.S. Synthesizing of nanostructured Fe-Mn alloys by mechanical alloying process. Procedia Mater. Sci. 2015, 11, 381-385. [CrossRef]

17. Sikora-Jasinska, M.; Chevallier, P.; Turgeon, S.; Paternoster, C.; Mostaed, E.; Vedani, M.; Mantovani, D. Understanding the effect of the reinforcement addition on corrosion behavior of $\mathrm{Fe} / \mathrm{Mg}_{2} \mathrm{Si}$ composites for biodegradable implant applications. Mater. Chem. Phys. 2019, 223, 771-778. [CrossRef]

18. Mouzou, E.; Paternoster, C.; Tolouei, R.; Purnama, A.; Chevallier, P.; Dubé, D.; Prima, F.; Mantovani, D. In vitro degradation behavior of Fe-20Mn-1.2 C alloy in three different pseudo-physiological solutions. Mater. Sci. Eng. C 2016, 61, 564-573. [CrossRef]

19. Mandal, S.; Ummadi, R.; Bose, M.; Balla, V.K.; Roy, M. Fe-Mn-Cu alloy as biodegradable material with enhanced antimicrobial properties. Mater. Lett. 2019, 237, 323-327. [CrossRef]

20. Faruk, M. Wear behaviour of hot rolled AZ31B magnesium alloy as candidate for biodegradable implant material. Trans. Nonferr. Met. Soc. China 2017, 27, 2598-2606.

21. Alshataif, Y.A.; Sivasankaran, S.; Al-Mufadi, F.A.; Alaboodi, A.S.; Ammar, H.R. Synthesis, microstructures and mechanical behaviour of $\mathrm{Cr}_{0.21} \mathrm{Fe}_{0.20} \mathrm{Al}_{0.41} \mathrm{Cu}_{0.18}$ and $\mathrm{Cr}_{0.14} \mathrm{Fe}_{0.13} \mathrm{Al}_{0.26} \mathrm{Cu}_{0.11} \mathrm{Si}_{0.25} \mathrm{Zn}_{0.11}$ nanocrystallite entropy alloys prepared by mechanical alloying and hot-pressing. Met. Mater. Int. 2021, 27, 139-155. [CrossRef]

22. Clinktan, R.; Senthil, V.; Ramkumar, K.R.; Sivasankaran, S.; Al-Mufadi, F.A. Effect of boron carbide nano particles in CuSi ${ }_{4} \mathrm{Zn}_{14}$ silicone bronze nanocomposites on matrix powder surface morphology and structural evolution via mechanical alloying. Ceram. Int. 2019, 45, 3492-3501. [CrossRef]

23. Sánchez, F.; Bolarín, A.M.; Molera, P.; Mendoza, J.E.; Ocampo, M. Relationship between particle size and manufacturing processing and sintered characteristics of iron powders. Rev. Latinoam. Metal. Mater. 2003, 23, 35-40.

24. Sivasankaran, S.; Sivaprasad, K.; Narayanasamy, R.; Iyer, V.K. An investigation on flowability and compressibility of AA 6061100-x-x wt.\% $\mathrm{TiO}_{2}$ micro and nanocomposite powder prepared by blending and mechanical alloying. Powder Technol. 2010, 201, 70-82. [CrossRef]

25. Cocks, A.C.F. Constitutive modelling of powder compaction and sintering. Prog. Mater. Sci. 2001, 46, 201-229. [CrossRef]

26. Rossi, R.; Alves, M.K.; Al-Qureshi, H.A. A model for the simulation of powder compaction processes. J. Mater. Process. Technol. 2007, 182, 286-296. [CrossRef]

27. Ammar, H.R.; Sivasankaran, S.; Alaboodi, A.S.; Al-Mufadi, F.A. Synthesis, microstructural investigation and compaction behavior of $\mathrm{Al}_{0.3} \mathrm{CrFeNiCo}_{0.3} \mathrm{Si}_{0.4}$ nanocrystalline high entropy alloy. Adv. Powder Technol. 2021, 32, 398-412. [CrossRef]

28. Li, H.; Zheng, Y.; Qin, L. Progress of biodegradable metals. Prog. Nat. Sci. Mater. Int. 2014, 24, 414-422. [CrossRef]

29. Liu, B.; Zheng, Y.F. Effects of alloying elements (Mn, Co, Al, W, Sn, B, C and S) on biodegradability and in vitro biocompatibility of pure iron. Acta Biomater. 2011, 7, 1407-1420. [CrossRef]

30. Alshataif, Y.A.; Sivasankaran, S.; Al-Mufadi, F.A.; Alaboodi, A.S.; Ammar, H.R. Synthesis, structure, and mechanical response of $\mathrm{Cr}_{0.26} \mathrm{Fe}_{0.24} \mathrm{Al}_{0.5}$ and $\mathrm{Cr}_{0.15} \mathrm{Fe}_{0.14} \mathrm{Al}_{0.30} \mathrm{Cu}_{0.13} \mathrm{Si}_{0.28}$ nanocrystallite entropy alloys. Adv. Powder Technol. 2020, 31, $2161-2177$. [CrossRef]

31. Sivasankaran, S.; Sivaprasad, K.; Narayanasamy, R.; Iyer, V.K. Evaluation of compaction equations and prediction using adaptive neuro-fuzzy inference system on compressibility behavior of $\mathrm{AA} 6061_{100-\mathrm{x}}-\mathrm{x}$ wt. $\% \mathrm{TiO}_{2}$ nanocomposites prepared by mechanical alloying. Powder Technol. 2011, 209, 124-137. [CrossRef]

32. Balshin, M.Y. Theory of compacting. Vestnik. Met. 1938, 18, 124-137.

33. Heckel, R.W. Density-pressure relationships in powder compaction. Trans. Met. Soc. AIME 1961, 221, $671-675$.

34. Rong-De, G. A new powder compaction equation. Int. J. Powder Metall. 1991, 27, 211-216. 
35. Panelli, R.; Ambrozio Filho, F. A study of a new phenomenological compacting equation. Powder Technol. 2001, 114, 255-261. [CrossRef]

36. Kawakita, K.; Lüdde, K.-H. Some considerations on powder compression equations. Powder Technol. 1971, 4, 61-68. [CrossRef]

37. Shapiro, I. Compaction of powders XII. Evaluation of published compaction equations for modeling purposes. Adv. Powder Met. Part. Mat. 1995, 1, 2.97-2.114.

38. Cooper, A.R., Jr.; Eaton, L.E. Compaction behavior of several ceramic powders. J. Am. Ceram. Soc. 1962, 45, 97-101. [CrossRef]

39. Zwan, J.V.D. The compaction and mechanical properties of some spray-dried ceramic materials. In Proceedings of the 10th International Conference 'Science of Ceramics', Berchtesgaden, W. Germany, 1-4 September 1979; Hausner, H., Ed.; Deutsche Keramische Gesellschaft: Bad Honnef, Germany, 1979; p. 159. 